\title{
Preparation, Characterization, and Biocompatibility Assessment of Polymer-Ceramic Composites Loaded with Salvia officinalis Extract
}

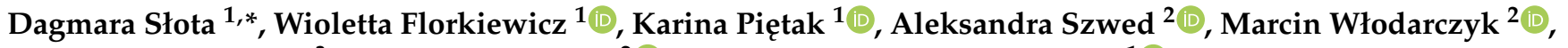 \\ Małgorzata Siwińska ${ }^{3}$, Karolina Rudnicka ${ }^{2} \mathbb{D}$ and Agnieszka Sobczak-Kupiec ${ }^{1}$ (D) \\ 1 Department of Materials Science, Faculty of Materials Engineering and Physics, Cracow University of \\ Technology, 37 Jana Pawła II Av., 31-864 Krakow, Poland; wioletta.florkiewicz@pk.edu.pl (W.F.); \\ karina.pietak6@gmail.com (K.P.); agnieszka.sobczak-kupiec@pk.edu.pl (A.S.-K.) \\ 2 Department of Immunology and Infectious Biology, Faculty of Biology and Environmental Protection, \\ University of Lodz, 12/16 Banacha, 90-237 Lodz, Poland; aleksandra.szwed@biol.uni.lodz.pl (A.S.); \\ marcin.wlodarczyk@biol.uni.lodz.pl (M.W.); karolina.rudnicka@biol.uni.lodz.pl (K.R.) \\ 3 Department of Biology of Bacteria, Faculty of Biology and Environmental Protection, University of Lodz, \\ 12/16 Banacha, 90-237 Lodz, Poland; malgorzata.siwinska@biol.uni.lodz.pl \\ * Correspondence: dagmara.slota@doktorant.pk.edu.pl
}

\section{check for} updates

Citation: Słota, D.; Florkiewicz, W. Piętak, K.; Szwed, A.; Włodarczyk, M.; Siwińska, M.; Rudnicka, K.; Sobczak-Kupiec, A. Preparation, Characterization, and Biocompatibility Assessment of Polymer-Ceramic Composites Loaded with Salvia officinalis Extract. Materials 2021, 14, 6000. https:// doi.org/10.3390/ma14206000

Academic Editor: Montserrat Colilla

Received: 30 August 2021

Accepted: 6 October 2021

Published: 12 October 202

Publisher's Note: MDPI stays neutral with regard to jurisdictional claims in published maps and institutional affiliations.

Copyright: (c) 2021 by the authors. Licensee MDPI, Basel, Switzerland. This article is an open access article distributed under the terms and conditions of the Creative Commons Attribution (CC BY) license (https:// creativecommons.org/licenses/by/ $4.0 /)$

\begin{abstract}
In the present work, hydroxyapatite-polymer materials were developed. The preparation, as well as characterization of the ceramic-polymer composites based on polyvinylpyrrolidone, sodium alginate, and gelatin were described. The system was enriched with the addition of common sage extract (Salvia officinalis). The antioxidant potential of sage aqueous extract and total polyphenol content was determined. The antioxidant capacity and total phenolic content of extract were equal to $86.06 \pm 0.49 \%$ and $16.21 \pm 0.58 \mathrm{mg}$ gallic acid equivalents per gram of dry weight, respectively. Incubation studies in selected biological liquids were carried out to determine the biomineralization capacity on the surface of the composites and to examine the kinetics of release of the active substances from within the material. As a result of the incubation, a gradual release of the extract over time from the polymer matrix was observed; moreover, the appearance of new apatite layers on the composite surface was recorded as early as after 14 days, which was also confirmed by energydispersive X-ray spectroscopy (EDS) microanalysis. The composites were analyzed with Fourier transform infrared spectroscopy (FTIR) spectroscopy, and the morphology was recorded by scanning electron microscope (SEM) imaging. The in vitro biological studies allowed their cytotoxic effect on the reference L929 fibroblasts to be excluded. Further analysis of the biomaterials showed that enrichment with polyphenols does not support the adhesion of L929 cells to the surface of the material. However, the addition of these natural components stimulates human monocytes that constitute the first step of tissue regeneration.
\end{abstract}

Keywords: common sage; Salvia officinalis; hydroxyapatite; ceramics; polyvinylpyrrolidone; composite

\section{Introduction}

Most organ and tissue damage resulting from congenital defects, trauma or chronic diseases is treated surgically, or pharmacologically. This includes the use of appropriate medications or, in more severe cases, organ transplants [1,2]. However, for some time now, great emphasis has been placed on intelligent, bioactive biomaterials, which offer great potential for regenerative medicine, by, among other things, stimulating the surrounding tissues or delivering active components such as drugs or biomolecules [3,4]. Such biomedical materials are widely used in orthopedics as implants, dressings and bone defect fillers and should have ideal biocompatibility, biodegradability and bioactivity [5,6]. In the case of bone tissue, the ability for osteoconduction as well as osteoinduction is also extremely important [7]. For bone tissue regeneration, all types of materials available are 
used, medical polymers, metals like titanium and its alloys but mainly it is bioceramics whose chemical composition is highly similar to that of natural bone $[8,9]$.

Bone is a heterogeneous composite material consisting of both organic and inorganic components [10]. The organic part, represented mainly by type I collagen fibrils, constitutes about $25-30 \%$ of the net weight of bone, about $60-70 \%$ is the mineral phase, and the remaining $5-10 \%$ is water $[11,12]$. The organic part provides flexibility and elasticity to the tissue, while the mineral part contributes to the stiffness and load bearing capacity of bone. The main component of the inorganic phase is the calcium phosphate ceramic, hydroxyapatite (HA) $\mathrm{Ca}_{10}\left(\mathrm{PO}_{4}\right)_{6}(\mathrm{OH})_{2}[13,14]$. Synthetic HA is widely used in medicine and dentistry in powder form for filling cavities or as a covering material for metallic implants [15]. It shows high biocompatibility as well as the ability to promote the infiltration of bone, bone marrow and blood vascular cells $[16,17]$. It is worth emphasizing that HA does not stimulate bone formation in the traditional sense, however, it directs its growth, which is referred to as osteoconductive action [18,19]. The limiting factors for HA applications are weakness in shear and tension as well as brittleness [20]. However, due to the ease of combining ceramics with other materials, especially polymers, these disadvantages can be overcome by suspending the ceramics in a polymer matrix, leading to a composite material. This results in a biomaterial with improved mechanical properties without losing the bioactive nature of HA [21,22].

In the present work, the polymer phase consisted of polyvinylpyrrolidone (PVP). It is an essential, water-soluble polymer approved by the U.S. Food and Drug Administration (FDA) as safe for body contact $[23,24]$. It shows excellent physiological compatibility, no toxicity and good adhesion $[25,26]$. For many years, it has been used in the medical industry as, for example, a component of contact lenses, a binder in pharmaceutical tablets and as a filler and binder in cosmetic products [27-29].

Common sage (Salvia officinalis), also called garden sage, kitchen sage or Dalmatian sage, is a plant of the Lamiaceae family, widely cultivated in the Mediterranean basin [30,31]. Besides its use as a popular spice, sage has been documented as a general tonic or medicine in consideration of its purported widespread medicinal properties [32]. The etymology of the Latin word Salvia is derived from the phrase salvare meaning "to cure" and salvere meaning "to be healthy". The second part, officinalis, which is a species name, refers to its common medicinal use [33]. In traditional medicine, it is used to treat various conditions, including diarrhea, gout, inflammation, rheumatism, ulcers, epilepsy and hyperglycemia [34]. According to the Pharmacopoeia, the pharmaceutical raw material of clary sage is the leaves and leafy shoot tips as these parts are the most rich in active substances [35]. Caffeic acid derivatives and widely distributed flavonoids, occurring mainly in the form of flavones (e.g., apigenin, luteolin and their respective 6-hydroxylated derivatives), flavonols and their glycosides (e.g., kaempferol and quercetin), play a significant role in sage activity [36,37]. By the presence of the mentioned components, the plant is attributed with antioxidant, antimicrobial, antiproliferative and anticarcinogenic properties [38]. Its ability to inhibit bone tissue resorption seems to be of particular interest [39]. Therefore, the combination of the osteoconductive properties of hydroxyapatite with the biological activity of sage may enhance bone regeneration.

The aim of this study was to develop a ceramic-polymer composite modified with plant extract using biocompatible PVP, bioactive HA showing osteoconductive properties and common sage extract to increase the biological value of the biomaterial. According to our best knowledge, any measurement methodology aimed at determining the structureproperty relationships in such ceramic-polymer composites modified with common sage extract has not yet been presented.

\section{Materials and Methods}

\subsection{Reagents}

Common sage (Salvia officinalis) dried leaves were purchased from Lord Nelson (Tarnowo Podgórne, Poland). All reagents used for HA synthesis, i.e., the sodium phos- 
phate dibasic $\left(\mathrm{Na}_{2} \mathrm{HPO}_{4}\right)$, calcium acetate monohydrate $\left(\mathrm{Ca}\left(\mathrm{CH}_{3} \mathrm{CO}_{2}\right)_{2} \cdot \mathrm{H}_{2} \mathrm{O}\right)$, ammonium phosphate monobasic and ammonia water $\left(\mathrm{NH}_{4} \mathrm{OH}, 25 \%\right)$ as well as sodium alginate (SA), polyvinylpyrrolidone (PVP), poly(ethylene glycol) diacrylate average Mn 700 (PEGDA), gelatin (GE), 2-hydroxy-2-methylpropiophenone 97\%, 2,2-Diphenyl-1-picrylhydrazyl (DPPH), triethanolamine $\geq 99.0 \%$ (TEA), gallic acid and edetate disodium were obtained from Sigma-Aldrich (Darmstadt, Germany). Urea was purchased from Stanlab (Lublin, Poland) and phosphate buffered saline (PBS) from Oxoid (Basingstoke, UK). The bismuth(III) nitrate pentahydrate $\left(\mathrm{Bi}\left(\mathrm{NO}_{3}\right)_{3}\right)$, sodium carbonate $\left(\mathrm{Na}_{2} \mathrm{CO}_{3}\right)$, potassium chloride $(\mathrm{KOH})$, sodium chloride $(\mathrm{NaCl})$, nitric acid $\left(\mathrm{HNO}_{3}\right)$, hydrochloric acid $(\mathrm{HCl})$, ethanol $96 \%$, calcium chloride dihydrate $\left(\mathrm{CaCl}_{2} \cdot 2 \mathrm{H}_{2} \mathrm{O}\right)$ and sodium sulfide nonahydrate $\left(\mathrm{Na}_{2} \mathrm{~S} \cdot 9 \mathrm{H}_{2} \mathrm{O}\right)$ were obtained from Chempur (Piekary Śląskie, Poland).

\subsection{Preparation of Hydroxyapatite}

Hydroxyapatite (HA) was synthesized by wet precipitation method performed at boiling temperature. Distilled water and a defined volume of $\mathrm{Na}_{2} \mathrm{HPO}_{4}(0.32 \mathrm{~mol} / \mathrm{L})$ were poured into a three-necked flask. Using $25 \%$ ammonia water, the $\mathrm{pH}$ of the system was brought to a level of 11 . Once the entire system was brought to a boil, $\left(\mathrm{CH}_{3} \mathrm{COO}\right)_{2} \mathrm{Ca}$ $(0.128 \mathrm{~mol} / \mathrm{L})$ was dropped in at a rate of $1 \mathrm{drop} / \mathrm{sec}$. After completion of the synthesis, the HA suspension was cooled down and set aside for $24 \mathrm{~h}$. After this time, the precipitate was washed thoroughly with distilled water, brought to neutral $\mathrm{pH}$ and dried [22].

\subsection{X-ray Diffraction Analysis}

To visualize the structure of HA, X-ray diffraction analysis was performed using a Malvern Panalytical Aeris X-ray diffractometer with PIXcel1D-Medipix3 detector (Malvern, $\mathrm{UK})$. The measurement was carried out at a step size of $0.0027^{\circ} 2 \theta$ in a $2 \theta$ range of $25-55^{\circ}$ with time per step $340.425 \mathrm{~s}$.

\subsection{Preparation of Common Sage Ectract}

The process of aqueous extraction of S. officinalis was carried out in a Soxhlet apparatus. For this purpose, a sample of dried sage was placed in an extraction thimble and distilled water was poured into a round-bottomed flask. The system was brought to a boil and the process was carried out for $12 \mathrm{~h}$.

\subsection{Preparation of Composites}

A $15 \%$ solution of PVP, a $1 \%$ solution of GE and a 1\% solution of SA were prepared to obtain mixtures for the production of composites. Appropriate amounts of such prepared solutions as well as HA powder were used to obtain the blends used in the preparation of composites. 2-hydroxy-2-methylpropion and PEGDA Mn 700 were used as a photoinitiator and crosslinking agent, respectively. The materials containing common sage extract were prepared by dissolving an appropriate amount of PVP in polyphenol solution. The detailed compositions of the composites are presented in Table 1.

Table 1. Composite materials composition.

\begin{tabular}{cccccccc}
\hline $\begin{array}{c}\text { Sample } \\
\text { Symbol }\end{array}$ & PVP $(\mathbf{m L})$ & $\begin{array}{c}\text { PVP in Sage } \\
\text { Extract }(\mathrm{mL})\end{array}$ & SA $(\mathbf{m L})$ & GE $(\mathrm{mL})$ & $\begin{array}{c}\text { PEGDA } \\
(\mathrm{mL})\end{array}$ & $\begin{array}{c}\text { Photoinitiator } \\
(\mu \mathrm{L})\end{array}$ & $\begin{array}{c}\text { Ceramic } \\
\text { Content }(\% \\
\boldsymbol{w} / \boldsymbol{v})\end{array}$ \\
\hline 17 & 7 & - & & & & - \\
17.1 & 7 & - & 3 & - & & 5 \\
17.2 & - & 7 & & & & 5 \\
25 & 7 & - & 1.5 & 1.5 & & & 5 \\
25.1 & 7 & - & & & & & 5 \\
25.2 & - & 7 & & & & \\
\hline
\end{tabular}


The components were mixed thoroughly and poured on a Petri dish. The photocrosslinking was performed using EMITA VP-60 lamp (Łódź, Poland) $(\lambda=320 \mathrm{~nm}$, $180 \mathrm{~W}$ ) for $4 \mathrm{~min}$.

\subsection{Fourier-Transform Infrared Spectroscopy Analysis}

To identify individual functional groups of the HA, PVP and sage samples, as well as to perform composite analysis before and after incubation period, Fourier transform infrared spectroscopy (FT-IR) was used. Analysis was performed with a Thermo Scientific Nicolet iS5 FT-IR spectrometer equipped with an iD7 ATR (Loughborough, UK) accessory operating at room conditions in the range of $4000-400 \mathrm{~cm}^{-1}$ (32 scans at $4.0 \mathrm{~cm}^{-1}$ resolution).

\subsection{Incubation in Vitro}

\subsection{1. pH-Metric Analysis}

To evaluate the bioactivity of the obtained sage composite materials in vitro, a $\mathrm{pH}$ metric study was performed. The purpose of this research was to confirm the interactions occurring between the sample and the incubation fluids. The molecules and ions contained in the fluids, interfering with the biomaterial, cause a change in $\mathrm{pH}$ value. Discs with mass of about $1 \mathrm{~g}$ were placed in simulated biological fluids, i.e., PBS, artificial saliva, and Ringer's fluid $(60 \mathrm{~mL})$. The biomaterials were incubated in POL-EKO incubator, model ST 5 B SMART (Wodzisław Ślaski, Poland) at $37^{\circ} \mathrm{C}$; for 14 days. The $\mathrm{pH}$ values were measured using pH-meter Elmetron CX-701 (Zabrze, Poland).

\subsubsection{Determination of Sorption Capacity of Biomaterials}

The composition of hydrogel materials may affect not only their structure but also the materials' swelling ability. To investigate this composition-swelling capacity relationship, a swelling kinetic study was proposed. The sorption capacity of materials was measured for disks with mass of about $1 \mathrm{~g}$. The aim of the study was to determine the amount of fluid that materials can absorb in a given time. For this purpose, the samples were placed in sterile containers filled with distilled water $(60 \mathrm{~mL})$ at $36.6^{\circ} \mathrm{C}$. After $15 \mathrm{~min}$, the sample was removed, excess liquid was collected with a filter paper and specimens were weighed. The measurement was repeated for all samples analogously at $15 \mathrm{~min}, 30 \mathrm{~min}, 1 \mathrm{~h}, 2 \mathrm{~h}$, $24 \mathrm{~h}, 7$ days, and 14 days. The swelling ratio $\left(S_{w}\right)$ was calculated using the following Equation (1):

$$
S_{w}=\frac{W_{t}-W_{0}}{W_{t}} \cdot 100 \%
$$

where $W_{t}$ is the weight of the swollen hydrogel sample and $W_{0}$ is the initial sample weigh.

The kinetic of swelling of the materials was investigated by Voigt-based viscoelastic model (Equation (2)):

$$
S_{t}=S_{e}\left[1-e^{-\frac{t}{\tau}}\right]
$$

where $S t$ is swelling at time $t$, Se is equilibrium swelling, $t$ is time for swelling $S t$, and $\tau$ means "rate parameter", defined as the time taken for the sample to reach 0.63 of its total swelling capacity. To determine $S e$ and $\tau$ results of the swelling capacity measurements were fitted to Equation (2) with the Origin software [40].

\subsection{Determination of Total Polyphenol Content}

The Folin-Ciocâlteu colorimetric assay was performed to determine the total polyphenol content (TPC) of the tested extracts. A supersaturated solution of $\mathrm{Na}_{2} \mathrm{CO}_{3}$ and a gallic acid solution of $5 \mathrm{mg} / \mathrm{mL}$ were prepared. The solutions were obtained by dilution of a working solution of gallic acid $\left(5 \mathrm{mg} \cdot \mathrm{mL}^{-1}\right)$ to the concentrations: $0.05 ; 0.15 ; 0.25 ; 0.35$; $0.5 \mathrm{mg} / \mathrm{mL}$ to form a calibration curve. Next, $20 \mu \mathrm{L}$ of calibration standards, $1.6 \mathrm{~mL}$ of distilled water, and $100 \mu \mathrm{L}$ of Folin-Ciocâlteu reagent were added to the cuvette. After approximately $3 \mathrm{~min}, 300 \mu \mathrm{L}$ of saturated $\mathrm{Na}_{2} \mathrm{CO}_{3}$ solution was added. The prepared 
samples were thoroughly pipetted to evenly mix, and placed in a thermostat for $30 \mathrm{~min}$ at $40{ }^{\circ} \mathrm{C}$.

Test samples of the resulting extracts were prepared in an identical manner, replacing the gallic acid solution with $20 \mu \mathrm{L}$ of extract of common sage, which had been diluted three times. Measurements were carried out at $765 \mathrm{~nm}$ against a blank, which was a sample without gallic acid. A Thermo Scientific, Genesys $180 \mathrm{UV}-$ Vis spectrophotometer (Loughborough, UK) was used for the measurements.

\subsection{Determination of Antioxidation by DPPH Method}

To investigate the antioxidant efficacy of the selected extracts, their ability to inactivate free radicals was examined. The antioxidant activity was determined using 2,2-Diphenyl1-picrylhydrazyl (DPPH). A solution of DPPH was prepared by dissolving $19.71 \mathrm{mg}$ of this compound in $100 \mathrm{~mL}$ of $96 \%$ ethanol. The resulting solution was then diluted to an absorbance value of about 0.9 . The control sample $A_{0}$ was prepared by adding $2 \mathrm{~mL}$ of the prepared DPPH solution and $60 \mu \mathrm{L}$ of $96 \%$ ethanol. Absorbance was measured on a UV-Vis spectrophotometer at $517 \mathrm{~nm}$. Samples with extracts of clary common sage were measured in an identical manner, replacing $60 \mu \mathrm{L}$ of ethanol with the selected extract. Absorbance was measured after approximately $10 \mathrm{~min}$ at room temperature at $517 \mathrm{~nm}$. Three replicates were made for each sample and averaged $(A)$. The antioxidant capacity of the test extract was calculated from the formula (3) [41].

$$
\% \text { inhibition }=\frac{A_{0}-A}{A_{0}} \cdot 100
$$

\subsection{Determination of Release Kinetics of Polyphenols}

In order to study the amount of release of the active ingredient from the obtained composites with common sage, an Electrolab EDT-081x (Mumbai, India) release water bath was used. The composite samples: 17.2 and 25.2 were placed in the release benches with stirring. Distilled water was then added and stirring was turned on at $36.6{ }^{\circ} \mathrm{C}$. After the specified time, $1 \mathrm{~mL}$ of solution was taken from each station, and $1 \mathrm{~mL}$ of distilled water was added to release benches. Samples were taken at intervals of: $15 \mathrm{~min}$, $30 \mathrm{~min}, 90 \mathrm{~min}, 1$ day, 2 days, 3 days, 4 days, 7 days, 10 days, and 14 days. The obtained samples were subjected to tests for determination of total polyphenol content (TPC) by the Folin-Ciocâlteu method [41].

\subsection{Morphology Analysis}

Surface morphology studies of the samples were performed using a Jeol 5510LV Scanning Electron Microscope (SEM) with an EDS IXRF System detector (Freising, Germany). SEM analysis was performed for the sake of comparing the surface of the composites before and after incubation period in artificial biological fluids to detect any changes as well as to record new apatite layers appearing on the surface of the samples.

Before the SEM measurement, the samples were freeze-dried and coated with nanolayer of gold.

\subsection{Cytocompatibility of the Composites}

\subsubsection{Sample Preparation for Biological Studies}

Prior to the biological evaluation, all composites were sterilized by gamma-irradiation (35 kGy gamma rays; ${ }^{60}$ Co source) at the Institute of Applied Radiation Chemistry, Technical University in Lodz (Lodz, Poland). The effectiveness of sterilization was confirmed by conventional microbiological techniques eri. Briefly, each type of sample was incubated in $5 \mathrm{~mL}$ of PBS/Tween buffer at room temperature $(15 \mathrm{~min}$./shaking) and $0.1 \mathrm{~mL}$ of the resulting liquid was transferred onto solid microbiological media for bacteria or yeast (Sabouraud agar): and incubated at $37^{\circ} \mathrm{C}$ for $24 \mathrm{~h}$ or 5 days, respectively.

For cytotoxicity (Section 2.12.3) and proinflammatory (Section 2.12.4) assay, composites were cut into pieces corresponding to one-tenth of the well surface area, as recommended 
by ISO 10993-5:2009 (Biological evaluation of medical devices-Part 5: Tests for in vitro cytotoxicity). To evaluate the composites in regard to cell expansion and adhesion by confocal microscopy imaging (Section 2.12.5) samples were cut into $7 \mathrm{~mm}$ diameter discs.

\subsubsection{Cell Culture Conditions}

The L929 (CCL-1) mouse skin fibroblasts recommended by ISO standards for biological evaluation of biomaterials with medical applications were obtained from the American Type Culture Collection (ATCC, Manassas, VA, USA). Prior to experiments, fibroblasts were cultured in Roswell Park Memorial Institute (RPMI)-1640 medium supplemented with 10\% heat-inactivated fetal bovine serum (FBS; HyClone Cytiva, Marlborough, MA, USA), penicillin (100U/mL), and streptomycin $(100 \mu \mathrm{g} / \mathrm{mL})$ (Sigma-Aldrich, Darmstadt, Germany) at a temperature of $37^{\circ} \mathrm{C}$, in a humidified air atmosphere containing $5 \% \mathrm{CO}_{2}$. To ensure that the cells formed confluent and homogeneous monolayers, the cell culture morphology was monitored using an inverted microscope (Motic AE2000 Xiamen, China). The confluent (80-90\%) cell monolayers were periodically subcultured using a $0.5 \%$ trypsin$0.5 \mathrm{mM}$ ethylenediaminetetraacetic acid tetrasodium salt (EDTA) solution (Gibco, Thermo Fisher Scientific, Waltham, MA, USA).

The THP1-Blue NF-kB human monocytes, carrying NF-kB-inducible SEAP (secreted embryonic alkaline phosphatase) reporter construct, were obtained from InvivoGen (San Diego, CA, USA). Monocytes were cultured in RPMI 1640 medium supplemented with $10 \%$ heat-inactivated FBS, $2 \mathrm{mM}$ L-glutamine, $100 \mathrm{U} / \mathrm{mL}$ penicillin, $100 \mu \mathrm{g} / \mathrm{mL}$ streptomycin, $25 \mathrm{mM}$ 4-(2-hydroxyethyl)-1-piperazineethanesulfonic acid (HEPES), $100 \mu \mathrm{g} / \mathrm{mL}$ normocin and $10 \mu \mathrm{g} / \mathrm{mL}$ blastocydin. The cell culture was conducted at $37^{\circ} \mathrm{C}$ in $5 \% \mathrm{CO}_{2}$ atmosphere and $90 \%$ humidity.

Prior to experiments, cell viability was established using a trypan blue exclusion assay. The cell suspensions with viability exceeding $90 \%$ were used in cytocompatibility experiments.

\subsubsection{Direct Contact Cytotoxicity Assay}

The metabolic activity of cells exposed to tested biomaterials was evaluated by 3-(4,5dimethylthiazol-2-yl)-2,5-diphenyltetrazolium bromide (MTT) reduction assay as described previously [42]. Briefly, L929 fibroblasts were introduced into 96-well cell culture plate (Nunclon Delta Surface, Nunc, Rochester, NY, USA) at a density of $2 \times 10^{4}$ cells per well and incubated overnight. Next, the previously prepared (Section 2.12.1) composites were added to cell monolayer (in six replicates). After overnight incubation, $20 \mu \mathrm{L}$ of MTT (Sigma-Aldrich, Darmstadt, Germany) was added and after $4 \mathrm{~h}$ incubation the supernatants were removed and replaced with $200 \mu \mathrm{L}$ of DMSO (dimethyl sulfoxide). Absorbance was determined calorimetrically at $570 \mathrm{~nm}$ with a MultiskanEX reader (Thermo Scientific, Waltham, MA, USA). The cell cultures in medium without the tested materials were used as a positive control of viability and cell cultures treated with $2 \%$ hydrogen peroxide served as a negative control of viability. The assay was performed in six replicates and three technical repeats.

\subsubsection{Monocyte Activation Assay}

To quantify the NF- $\mathrm{KB}$ induction activated in monocytes by obtained composites THP-1Blue NF- $\mathrm{kB}$ reporter cell line was used. The assay was performed as described previously [42]. Briefly, THP1-Blue NF- $\mathrm{kB}$ monocytes were adjusted to $5 \times 10^{5}$ cells $/ \mathrm{mL}$ and $200 \mu \mathrm{L}$ of cell suspension was transferred to each well. Next, previously prepared (see Section 2.12.1) composites were added to selected wells (in six replicates) and after 24-h incubation at $37^{\circ} \mathrm{C}$ in $5 \% \mathrm{CO}_{2}$ atmosphere, the concentration of alkaline phosphatase in supernatants was measured using the QUANTI-Blue reagent (InvivoGen, San Diego, CA, USA) according to the manufacturer's instructions. The quantification of media color change was performed with a Multiskan EX reader (Thermo Fisher Scientific, Waltham, MA, USA) at $650 \mathrm{~nm}$. The monocytes activated with phorbol 12-myristate 13-acetate (PMA) 
at $100 \mathrm{ng} / \mathrm{mL}$ were used as positive control of NF- $\mathrm{KB}$ activation, whereas untreated cells were used as a negative control of activation. The assay was performed in six replicates and three technical repeats.

\subsubsection{Composite Colonization by Cells}

To fully address the question whether obtained composites facilitate cell adhesion and expansion on their surface, we have visualized cells colonizing each material after 5 days culture. Previously prepared composites (Section 2.12.1) were placed in an individual well of the nonadherent Nunclon Delta Surface 24-well culture plate (Nunc, Thermo Fisher Scientific, Waltham, MA, USA) in three replicates each. Then $20 \mu \mathrm{L}$ of L929 cell suspension $\left(2 \times 10^{5}\right.$ cells) was spotted at the center of each biomaterial and the composites were incubated for $2 \mathrm{~h}$ in a humidified $5 \% \mathrm{CO}^{2}$ atmosphere at $37^{\circ} \mathrm{C}$. After initial adhesion, the wells were filled with $1 \mathrm{~mL}$ of fresh medium and incubated for 5 days. Following incubation, the culture medium was removed and composites were washed with phosphate buffered saline (PBS). Next, the cells were fixed with 3.7\% paraformaldehyde (Sigma-Aldrich, Saint Louis, MO, USA) for $20 \mathrm{~min}$ at room temperature, followed by permeabilization (15 $\mathrm{min}$, $0.1 \%$ Triton X-100 in PBS). The nuclei were stained with $300 \mathrm{nM} 2$-(4-amidinophenyl)-1Hindole-6-carboxamidine (DAPI) and actin filaments with phalloidin conjugated with iFluor 594 (Cayman Chemical, Ann Arbor, MI, USA) diluted 1:1000 in PBS containing 1\% BSA. The confocal laser scanning macroscopy platform TCS LSI (Leica Microsystems, Frankfurt, Germany) with the objective $5 \times / 0.50$ LWD (Leica Microsystems) was used for microscopic imaging. Samples were imaged with the following wavelength values of excitation and emission: 405 and 430-480 nm for DAPI, 590 and 615-630 nm for iFluor 594 conjugated antibody. Leica Application Suite X (LAS X; Leica Microsystems) was used for cell imaging.

\subsubsection{Statistical Analysis}

The results were subjected to statistical analysis with the use of SigmaPlot 12.0 software (San Jose, CA, USA). In the case of normal data distribution, the t-test was used and Mann-Whitney rank sum test was used when the distribution was recognized as normal. To assess the significance of differences between particular composites, ANOVA test was conducted and for significant comparisons further analysis using the Luke's method was employed. The differences were considered significant when a $p$-value $<0.05$.

\section{Results}

\subsection{X-ray Diffraction Analysis}

The result of XRD analysis of HA powder is presented in Figure 1. The analysis showed that the obtained material was phase pure, and the only phase identified in the X-rays was HA. The result appeared to be consistent with the phases listed in the ICDD database File Card No. 01-080-7085, and the XRD reflections were assigned to the hexagonal structure (P63/m space group) of HA with the lattice parameters a $=9.4172 \AA$ and c $=6.8799 \AA$ [43].

\subsection{Fourier-Transform Infrared Spectroscopy Analysis}

Figure 2 presents the absorption spectra for pure components as well as composites. The absorption band of the PEGDA sample at $2858 \mathrm{~cm}^{-1}$ was attributed to the C-H stretching vibration, while $790 \mathrm{~cm}^{-1}$ represented the $\mathrm{C}-\mathrm{H}$ bending mode. These $\mathrm{C}-\mathrm{H}$ stretching vibrations are also clearly visible in composites and PVP. The peak at $1727 \mathrm{~cm}^{-1}$ was observed in association with the $\mathrm{C}=\mathrm{O}$ stretching frequency [44]. This peak was also clearly visible on the spectrum of samples 17, 17.2, 25, and 25.2. The peak observed at $1458 \mathrm{~cm}^{-1}$ is attributed to symmetric bending of the $\mathrm{CH}_{2}$ group. In addition, the bands located at $1345 \mathrm{~cm}^{-1}$ and $1245 \mathrm{~cm}^{-1}$ were marked and were consistent with asymmetric C-O bending, while peaks at $1089 \mathrm{~cm}^{-1}, 985 \mathrm{~cm}^{-1}$, and $946 \mathrm{~cm}^{-1}$ represented C-O-C stretching. The absorption bands indicated by the red dashed line were attributed to symmetric $\mathrm{C}=\mathrm{C}$ stretching [45]. 
Spectral analysis of HA revealed the presence of phosphate groups as evidenced by distinct bands in the $550-1016 \mathrm{~cm}^{-1}$ range. The band in the wavelength range from $550 \mathrm{~cm}^{-1}$ to $578 \mathrm{~cm}^{-1}$ was associated with a triple degenerate O-P-O bending mode in $\mathrm{PO}_{4}{ }^{3-}$ groups which occupy two sites in the crystal lattice [46]. Characteristic of HA, the intense peaks associated with asymmetric P-O stretching vibrations were attributed to $1016 \mathrm{~cm}^{-1}$ while the band observed at $845 \mathrm{~cm}^{-1}$ corresponds to the presence of carbonate ions $[47,48]$.

Analysis of the spectra of the composites clearly showed the peaks coming from the PVP. This was particularly noticeable for the peak at $1645 \mathrm{~cm}^{-1}$ attributed to the $\mathrm{C}=\mathrm{O}$ bond [49]. At $1418 \mathrm{~cm}^{-1}, \mathrm{C}-\mathrm{H}$ bending was observed and $1265 \mathrm{~cm}^{-1}$ was attributed to $\mathrm{CH}_{2}$ wagging [50]. It is worth noting that the peak for $\mathrm{C}-\mathrm{H}$ bending was also observed in GE and SA, which was due to the chemical similarity of these polymers. Composites 17.2 and 25.2 clearly showed a signal from HA at $550 \mathrm{~cm}^{-1}$. However, the other signal expected to be seen in the composites, corresponding to asymmetric P-O stretching vibrations overlapped with the signal obtained from SA. This peak was attributed to the elongation of $\mathrm{C}-\mathrm{O}$ groups occurring in SA [51].

\subsection{Incubation In Vitro}

\subsection{1. $\mathrm{pH}-$ Metric Analysis}

Incubation studies were conducted to determine what would happen to the synthesized composites when immersed in fluids similar in composition to those found in the human body. According to the results of the study (Figure 3), it was possible to observe the curves showing the $\mathrm{pH}$ changes for all the tested composite samples subjected to incubation experiments. The tested materials were incubated in four different fluids, namely distilled water, PBS, Ringer's fluid and artificial saliva. It can be clearly observed that the tested composites had an effect on the $\mathrm{pH}$ of the tested fluids.

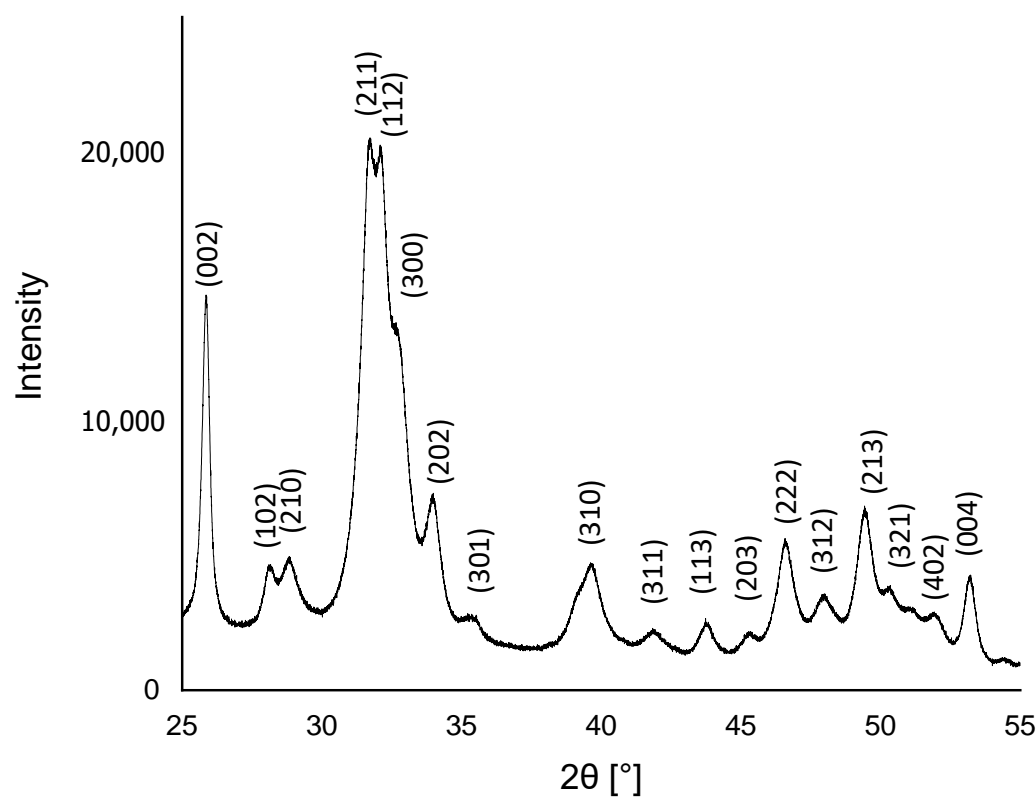

Figure 1. XRD spectrum of HA obtained by wet precipitation method. 


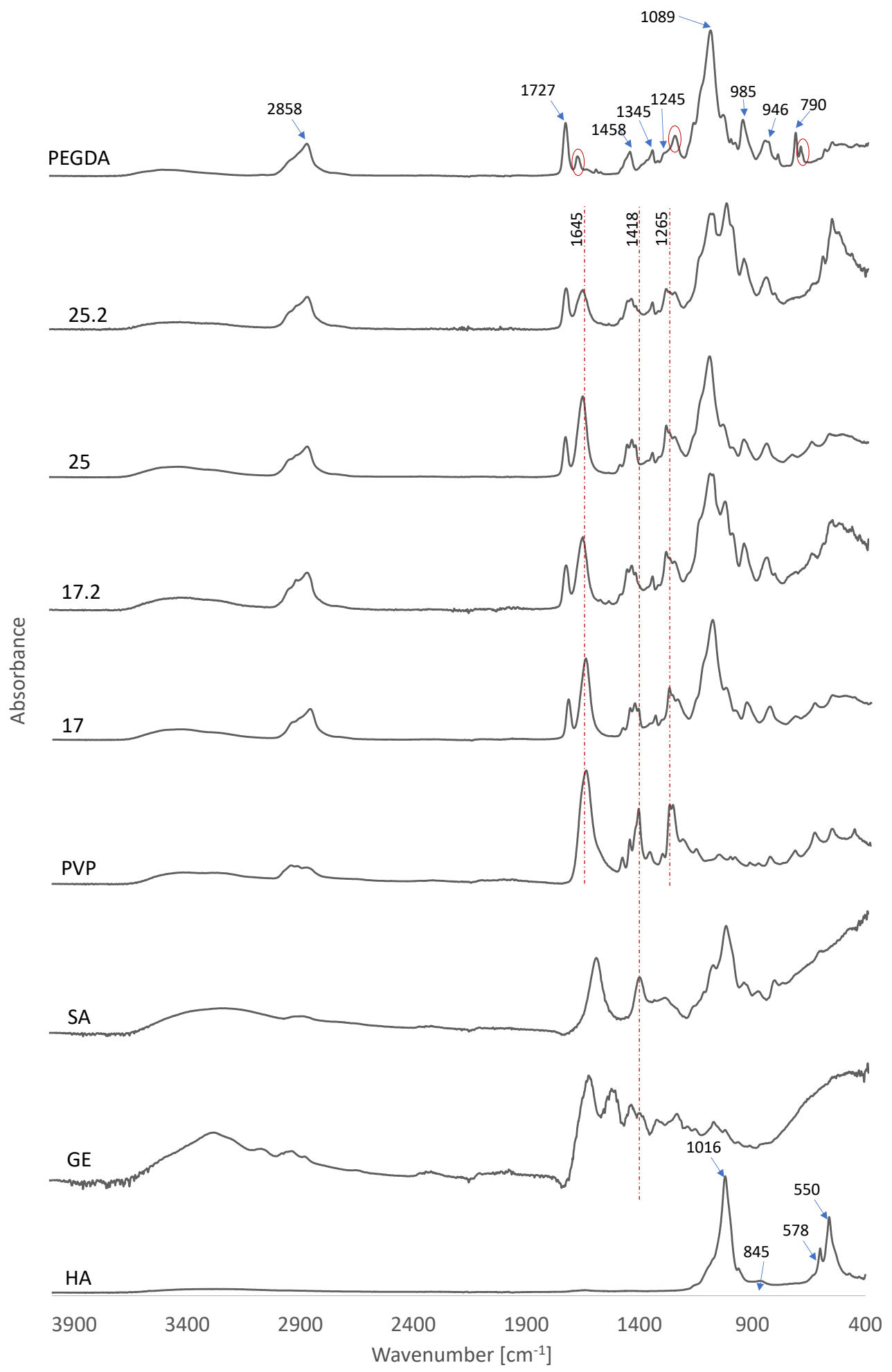

Figure 2. FTIR spectra of PEGDA, PVP, GE, SA, and composites. 


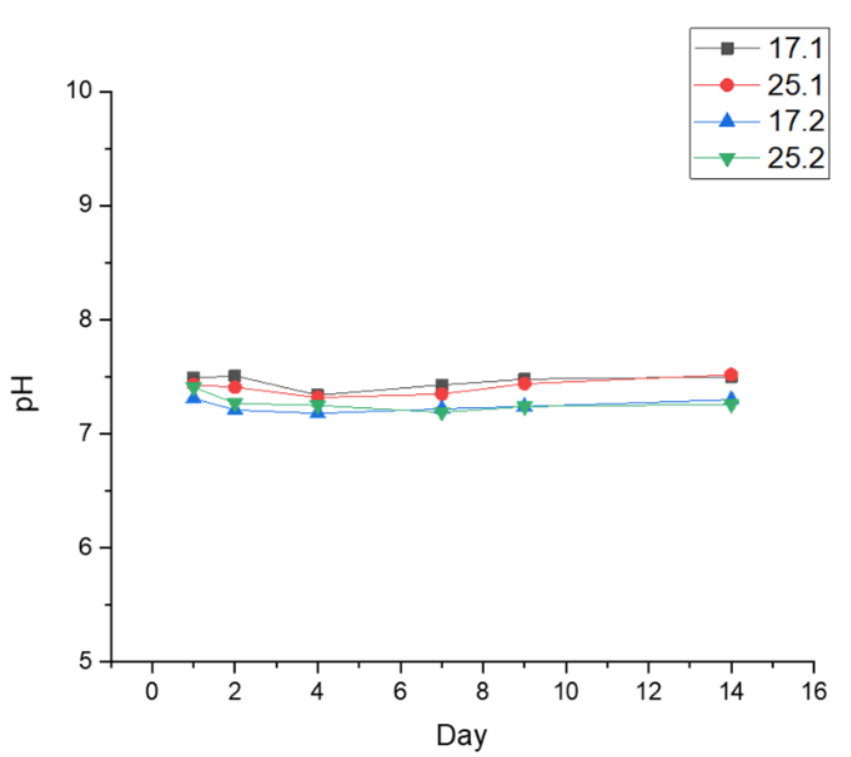

(a)

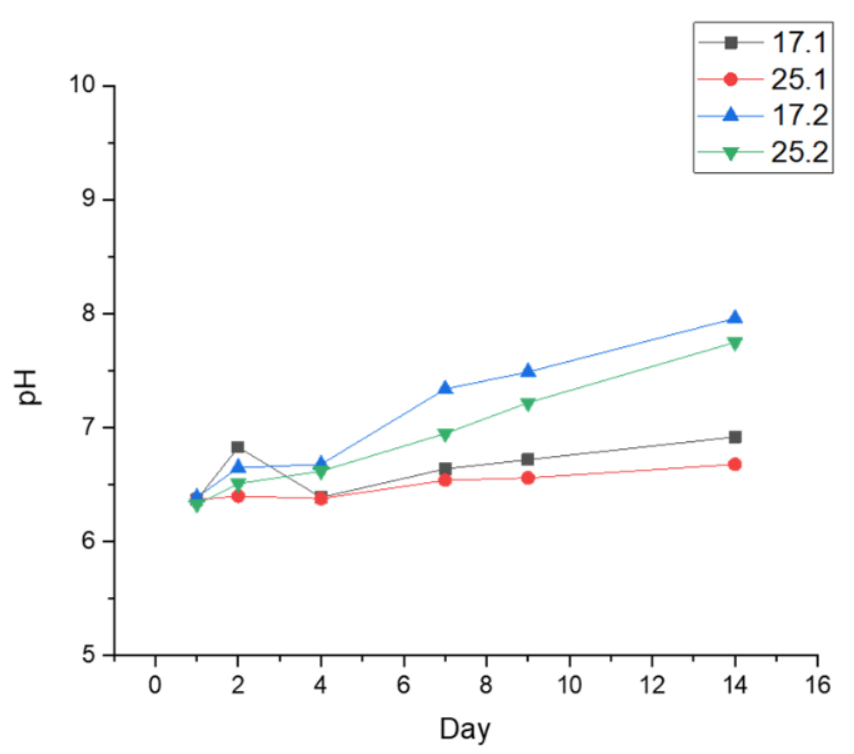

(c)

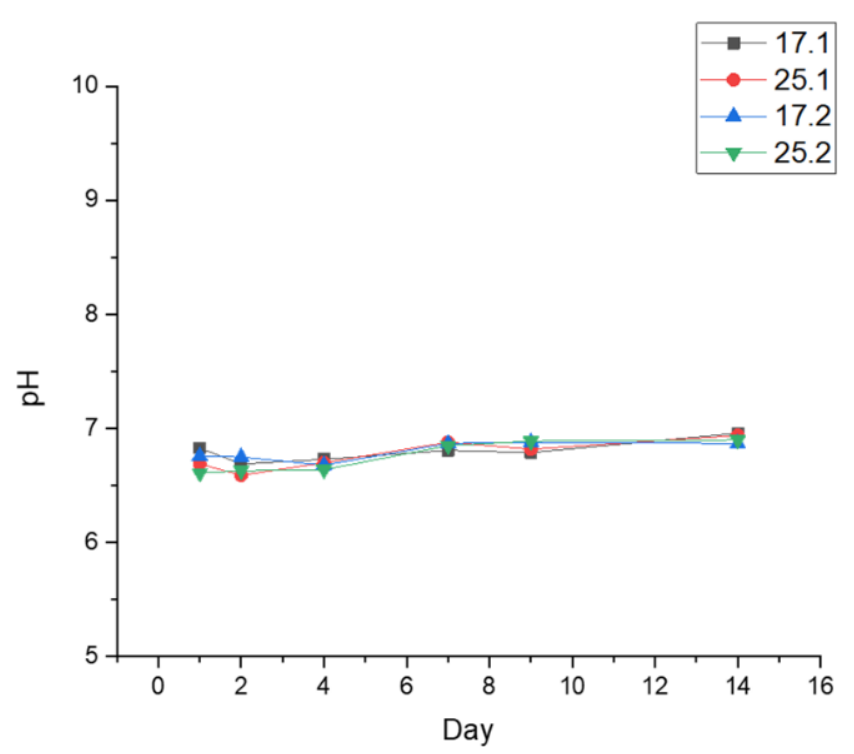

(b)

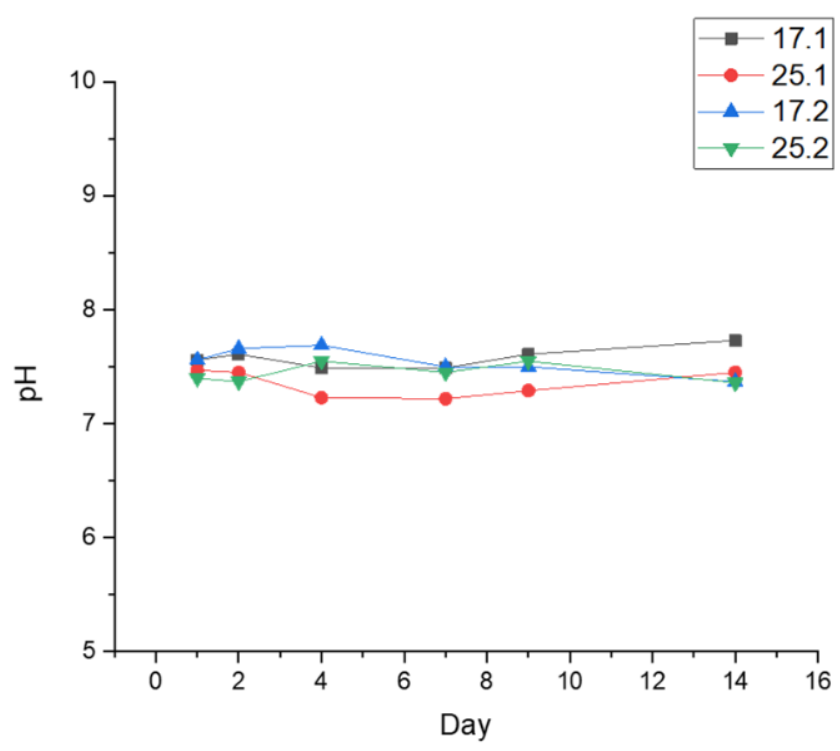

(d)

Figure 3. Measured pH values of: (a) PBS; (b) Ringer's fluid; (c) artificial saliva; (d) distilled water.

The greatest changes in $\mathrm{pH}$ values were noticed for the samples immersed in the artificial saliva solution. There, partial degradation was also observed. Probably, this is related to the slightly acidic reaction of the fluid, whose initial value was 5.5. Therefore, it could cause the degradation process of the samples, and the substances as well as ions released from it during this process significantly influenced the $\mathrm{pH}$ change. Moreover, it could also be the result of partial elution of HA from the interior of the sample, as this inorganic compound is poorly soluble in such solutions and as a result the solution becomes slightly basic [52]. In the case of distilled water, there were no free ions in the incubation medium that could interact with the test samples and thus significantly affect the $\mathrm{pH}$. Therefore, the observed $\mathrm{pH}$ changes were relatively small. Additionally, during incubation of the samples in the other fluids, i.e., PBS and Ringer's fluid, no rapid changes were observed, and the $\mathrm{pH}$ value remained very similar despite the rich chemical composition of the incubation media. This is probably related to the formation of new apatite layers on the surface resulting from the presence of calcium ions in the fluids. This may limit the 
degradation process and thus the rapid changes in $\mathrm{pH}$ value. In addition, this observation may be due to the buffering properties of the composites, which lie in their ability to maintain the $\mathrm{pH}$ of the solution at the same level [53]. Such observations may indicate that the composites analyzed can be considered biocompatible with the selected fluids.

\subsubsection{Determination of Sorption Capacity of Biomaterials}

The swelling rate of hydrogels is an important parameter that controls the release patterns of solvents, drugs, and other active substances from polymer networks. The observed lower sorption capacity for composites compared to polymer matrices is probably caused by the presence of ceramics. HA powder is physically filled into the polymeric network by occupying "free spaces" in the polymer network, which can hinder the diffusion of water molecules [54]. The addition of HA has been shown to generate more crosslinking points in the polymer network, resulting in a reduction in the flexibility of the polymer chains, as well as a reduction of hydrophilic groups on the composite backbone [55]. The entire swelling process is related to the penetration of water into the matrix of the dry material and subsequent hydration of the most polar hydrophilic groups. As a consequence, the hydrogel swells, the hydrophobic groups are exposed, and they also begin to interact with water. As a result of the exposure of polar and hydrophobic sites, the polymer network has the ability to absorb additional water due to the osmotic pressure created $[56,57]$. The additional amount of absorbed water fills the free spaces between the polymer chains. Therefore, even small values of swelling of the material are a satisfactory result, because it is a sign of the possibility of using such a system in delivering active substances, since as a result of swelling of the hydrogel, small particles of, e.g., a drug are released. Figure 4 presents the kinetics of swelling of the tested materials. $S_{e}$ and $\tau$ values for all specimens are summarized in Table 2.

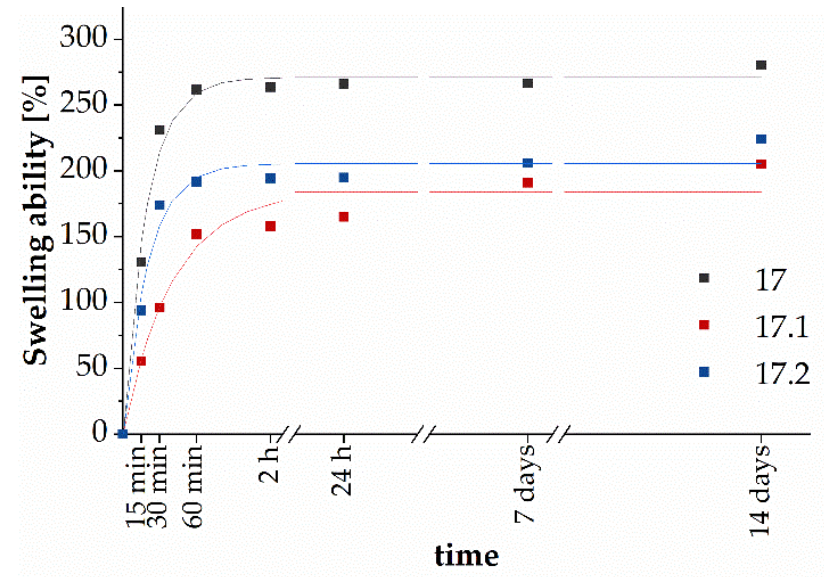

(a)

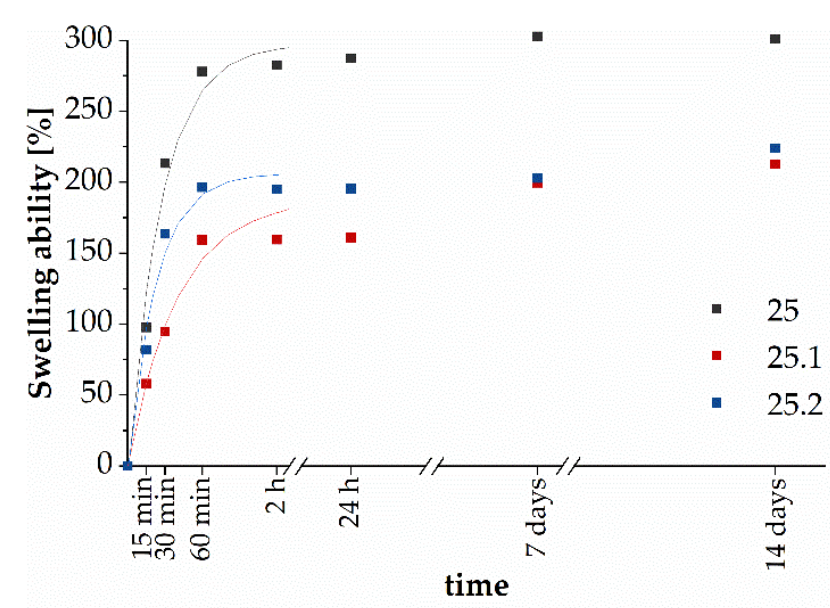

(b)

Figure 4. Kinetics of swelling of samples 17, 17.1, and 17.2 (a), and 25, 25.1, and 25.2 (b).

Table 2. Rate parameter $(\tau)$ and equilibrium swelling $\left(S_{e}\right)$ values of investigated materials.

\begin{tabular}{ccc}
\hline Sample & $\boldsymbol{S}_{\boldsymbol{e}} \mathbf{( \% )}$ & $\boldsymbol{\tau}$ (Minutes) \\
\hline 17 & $271.0 \pm 5.7$ & $19.0 \pm 2.1$ \\
17.1 & $183.9 \pm 8.4$ & $37.2 \pm 8.3$ \\
17.2 & $205.5 \pm 6.7$ & $20.1 \pm 3.3$ \\
25 & $279.1 \pm 8.3$ & $26.7 \pm 3.5$ \\
25.1 & $187.8 \pm 10.8$ & $40.0 \pm 8.5$ \\
25.2 & $216.3 \pm 7.0$ & $24.7 \pm 3.7$ \\
\hline
\end{tabular}


As can be observed in Figure 4 in the initial incubation period, the swelling ability increased and then stabilized over time. The samples were characterized with different maximum swelling capacities being in the range of $205-300 \%$. However, it is worth noticing that $S e$ and $\tau$ values were greater for series 25 . Then, it can be concluded that the addition of GE increases the swelling ability of materials, and simultaneously leads to slower liquid medium absorption. For both samples 17.1 and 25.1 containing the ceramic phase, a decrease in sorption capacity was visible. These samples demonstrated the lowest $S_{e}$, but rate parameters were the highest. Therefore, it can be concluded that the addition of the ceramic phase inhibits penetration of the liquid medium into the interior of the samples. Interestingly, the presence of plant extract in the materials results in an increase in the $S_{e}$ values and faster liquid absorption at the initial stage of immersion in comparison with 17.1 and 17.2 samples. However, $S_{e}$ values are lower in comparison with unmodified samples (17 and 25). This may be caused by hydrogen bonds forming between substances contained in extract and polymers chains, which initially slowed liquid absorption, however, further incubation led to extract elution resulting in greater $S_{e}$ values in comparison with composites 17.1 and 25.1.

\subsection{Determination of Total Polyphenol Content}

The total polyphenol content (TPC) was determined using the Folin-Ciocalteu (F-C) method. This method takes advantage of the ability of polyphenols to react colorfully with Folin's reagent. Phenolic compounds present in the sample were oxidized and the salts of phosphomolybdenum and phosphotungstic acids, which are components of the $\mathrm{F}-\mathrm{C}$ reagent, were reduced in an alkaline medium - the resulting reaction product was blue in color [58]. The TPC for sage extract was expressed as gallic acid equivalent per one gram of dry weight (mg GAE, $\mathrm{g}^{-1}$ d.w.), and equals $16.21 \pm 0.58 \mathrm{mg} \mathrm{GAE} \cdot \mathrm{g}^{-1}$ d.w.

\subsection{Determination of Antioxidation by DPPH Method}

The DPPH method was used to determine the antioxidant potential of common sage. According to it, 2,2-diphenyl-1-picrylhydrazyl (DPPH) radical, which is a dark purple crystalline solid, was mixed with the plant extract and the decrease in absorbance at $517 \mathrm{~nm}$ was measured [59]. The antioxidant capacity of common sage was presented as a percentage of inhibition, and the value reached $86.06 \pm 0.49 \%$.

\subsection{Determination of Release Kinetics of Polyphenols}

Sage extract was entrapped during composite preparation, as described in Section 2.5. The preparation of the composites, and then their release behavior was examined (Figure 5). Initially, samples 17.2 and 25.2 contained the same amount of polyphenol in PVP solution. The obtained results showed the release of polyphenol at similar rates for both samples 17.2 and 25.2 during the $90 \mathrm{~min}$ of incubation. However, after 1 day of incubation, the TPC content in the liquid medium was greater for sample 25.2. This trend was observed during further incubation. These results are consistent with the swelling capacity measurement, which showed a higher Se value for specimen 25 . The higher swelling ability of the materials led to more effective extract release. Thus, it can be concluded that the addition of GE increases the amount of extract released from materials. During the release of sage extract, it is particularly significant that the process was gradual, not rapid, or abrupt. 


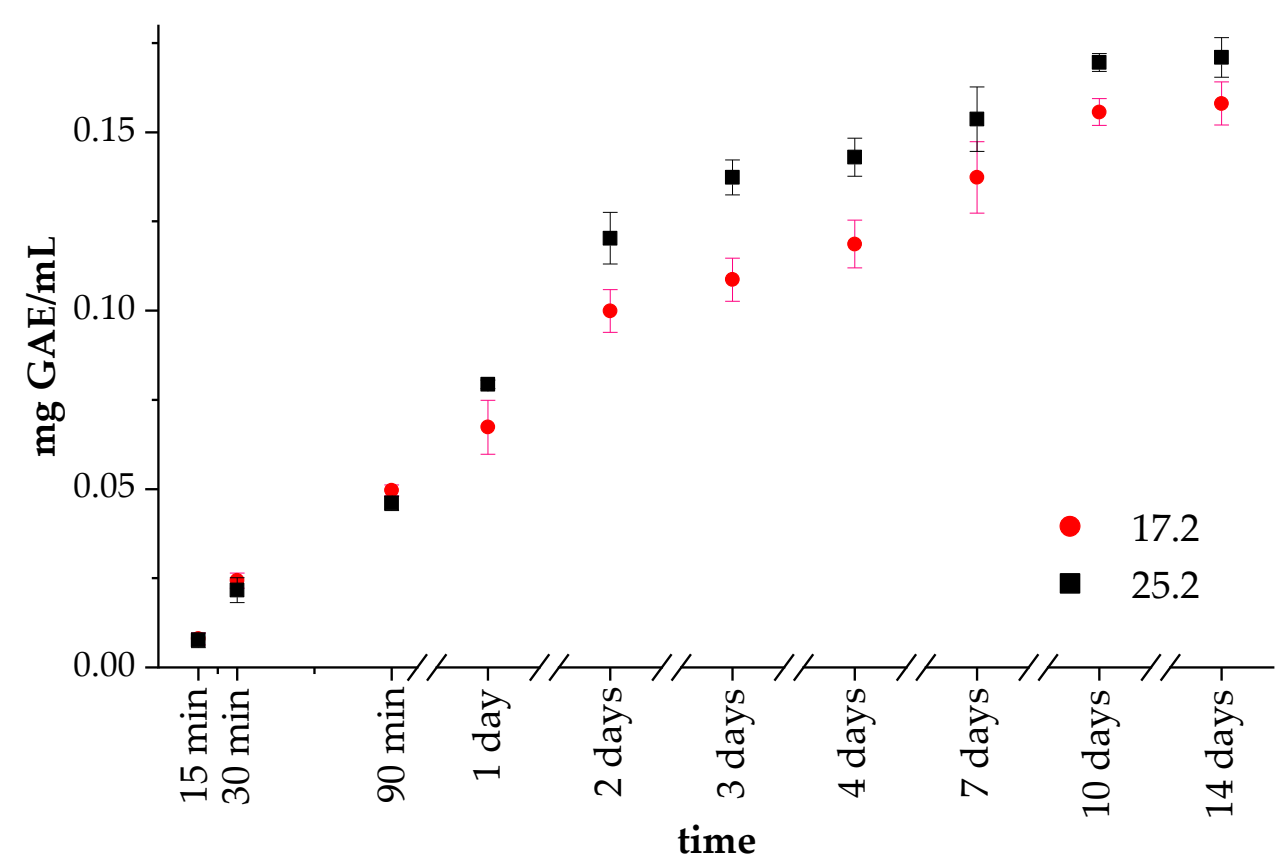

Figure 5. Release profiles of extract from samples 17.2 and 25.2.

\subsection{Morphology Analysis}

The composites were incubated for 14 days in selected artificial biological fluids. Due to the chemical composition of PBS (especially the presence of Ca and P ions) and possible interactions between PBS and the material, the most interesting results were obtained in this liquid (Figure 6). Comparing the surface of the material before and after the incubation period, it was clear that new apatite layers had appeared on their surface. The appearance of such apatite layers as well as crystals on the surface of the incubated materials is the most desirable result, as the observed biomineralization indicates the bioactivity of the composite. This confirms the interaction between the sample and the incubation fluid. Moreover, the ability to form mineralized apatite layers on the surface of incubated samples is highly dependent on the presence of HA in the biomaterial. A higher percentage of ceramic in the composite would likely result in the appearance of even more apatite layers.

For a more detailed analysis, EDS was additionally performed to determine the presence of individual elements (Figure 7). The presence of Au is related to the need for gold sputtering prior to SEM analysis.

Detailed EDS analysis for the presence of each element is shown in Table 3. The presence of a considerable number of $C$ atoms was noticeable in each sample, which was closely related to the composition of the polymer matrix. The detection of $\mathrm{K}, \mathrm{Na}$ and $\mathrm{Cl}$ ions after incubation indicates the occurrence of the desired reactions between the biomaterial and the artificial physiological fluid. In addition, analysis of the elemental composition of the composites also indicates significant amounts of $\mathrm{Ca}$ and $\mathrm{P}$, which are the basic elements of hydroxyapatite ceramics. 


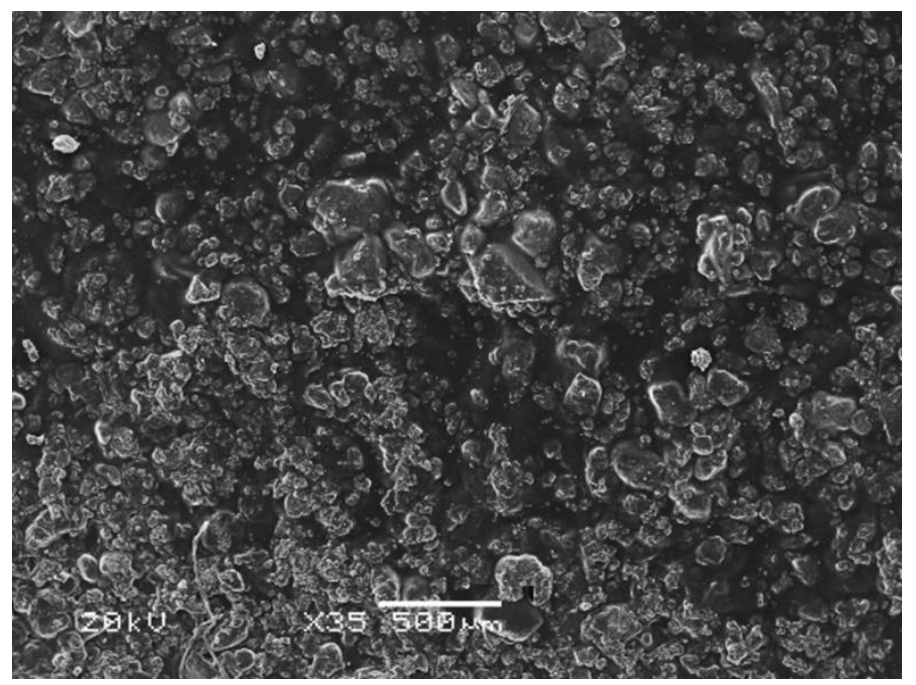

(a)

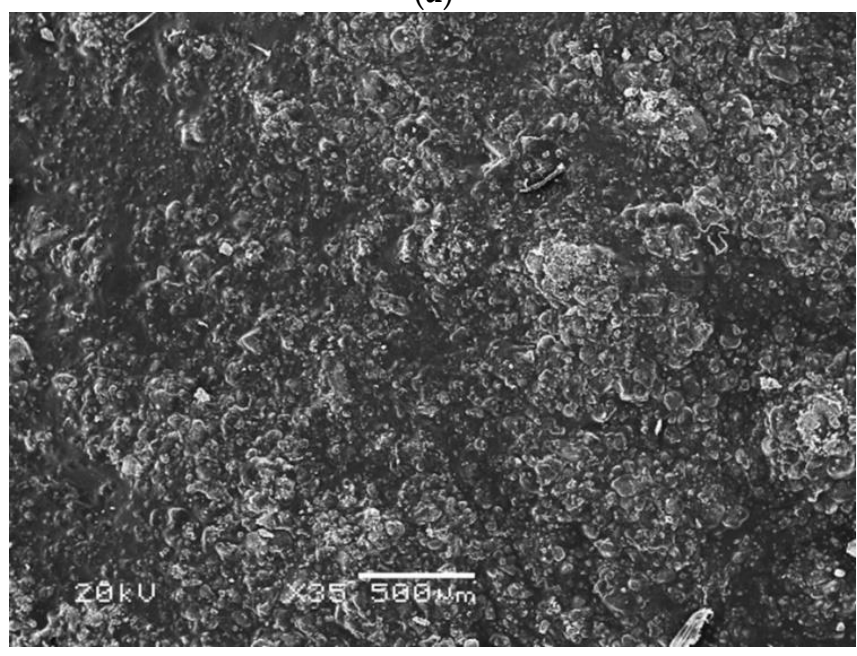

(c)

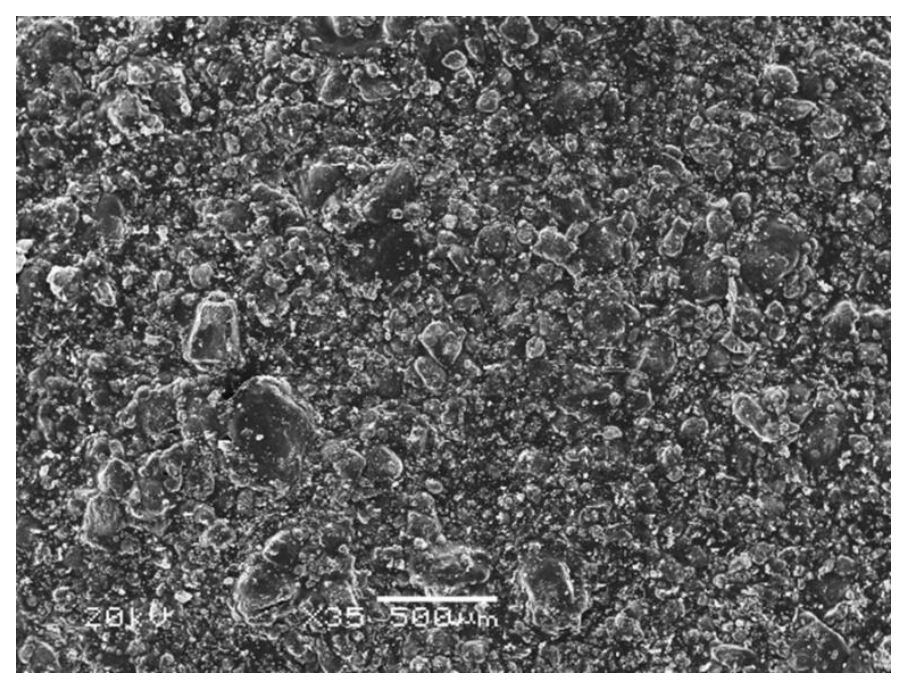

(b)

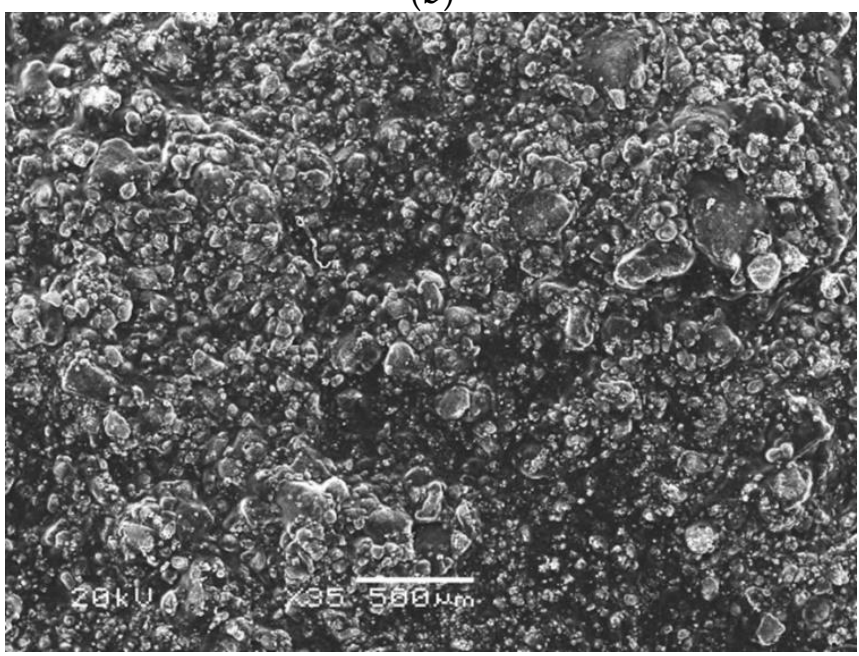

(d)

Figure 6. Morphology analysis of the composites (a) 17.2. before incubation; (b) 17.2 after incubation in PBS; (c) 25.2 before incubation; (d) 25.5 after incubation in PBS.

For samples incubated in artificial saliva solution, progressive degradation was observed, presumably due to the effect of the slightly acidic $\mathrm{pH}$ of the fluid, on the polymeric matrix. In the case of Ringer's fluid, it seemed that blooming of new apatite crystals could be observed on the sample, however, after deeper analysis, it was determined that the polymeric matrix degrades slowly, exposing HA crystals already encapsulated in the polymeric network during the synthesis step. Nevertheless, it is worth noting that in this case, due to the slightly higher $\mathrm{pH}$, the degradation process was slower than in the case of the samples immersed in artificial saliva. 


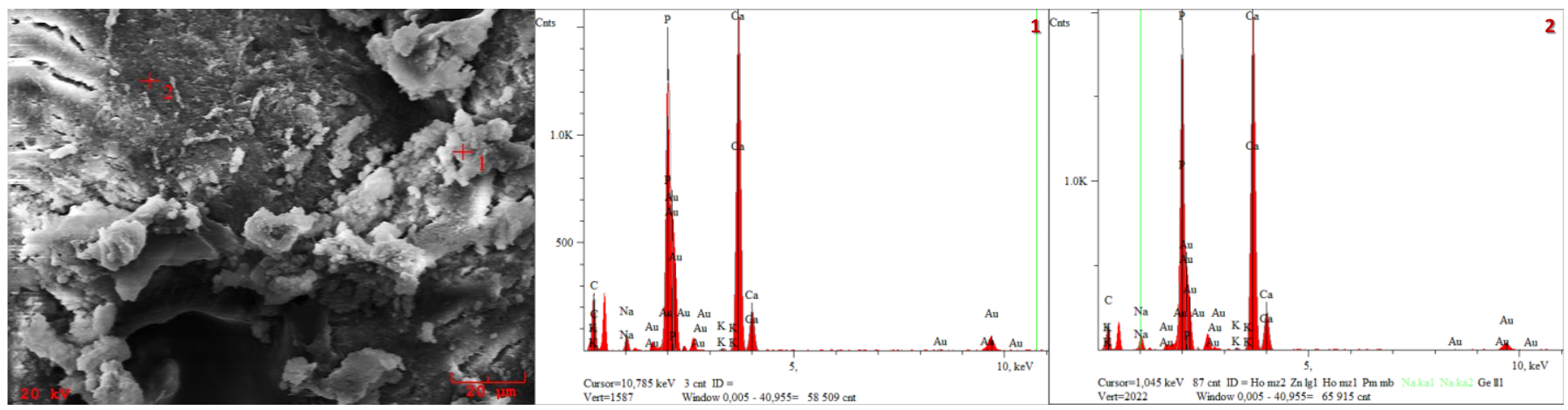

(a)
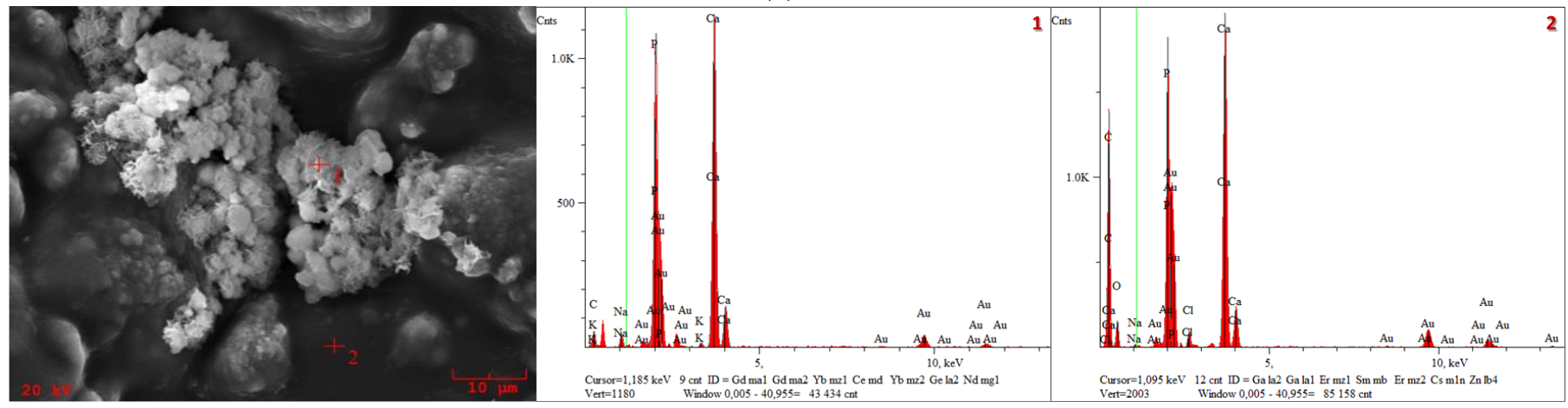

(b)

Figure 7. SEM morphology and EDS microanalysis of the composites: (a) 17.2; (b) 25.2.

Table 3. Elemental composition of composites after incubation in PBS.

\begin{tabular}{ccc}
\hline Sample & Spot & Atomic Percentage (wt. \%) \\
\hline \multirow{2}{*}{17.2} & 1 & C: $64.19 ;$ Na: $1.54 ;$ P: $15.38 ;$ K: $0.12 ;$ Ca: 18.75 \\
& 2 & C: $49.03 ;$ Na: $2.35 ;$ P: $20.22 ;$ K: 0.17; Ca: 28.23 \\
\hline \multirow{2}{*}{25.2} & 1 & C: 41.09; Na: 2.52; P: 25.64; K: 0.39; Ca: 30.34 \\
& 2 & C: 71.26; O: 13.15; Na: 0.17; P: 6.07; Cl: 0.38; Ca: 8.961 \\
\hline
\end{tabular}

3.8. Biological Properties of the Composites

3.8.1. In Vitro Cytocompatibility of Composites

The effect of polyvinylpyrrolidone/sodium alginate/hydroxyapatite composites enriched with polyphenols extracted from common sage (Salvia officinalis) on the metabolic activity of the mitochondrial dehydrogenases of the reference L929 murine fibroblasts was evaluated in MTT reduction assay. As shown in Figure 8, all the tested biocomposites did not affect the viability of murine L929 fibroblasts after $24 \mathrm{~h}$ of incubation. 


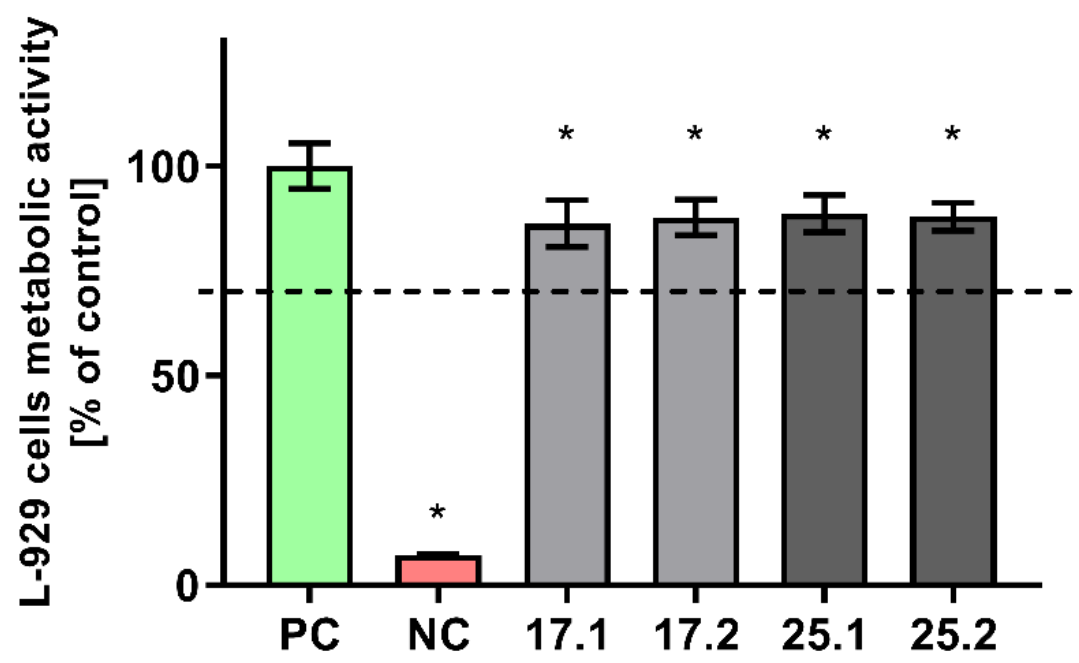

Figure 8. The viability of murine fibroblasts (L-929) after $24 \mathrm{~h}$ incubation with biocomposites, evaluated using MTT reduction test according to ISO-10993-5:2009. The positive control (PC) of the viability $(100 \%)$ consisted of cells incubated without composites. The negative control (NC) of the viability (cells with significantly impaired metabolic activity) consisted of cells incubated with $0.3 \%$ hydrogen peroxide. The data are presented as mean $\pm S D, n=6$. The dashed line indicates the minimum level $(70 \%)$ of the cells' metabolic activity required to recognize the biomaterial as noncytotoxic at the in vitro level. ${ }^{*} p$ values $(<0.05)$ calculated in comparison to the NC.

The viability of murine fibroblasts exposed to 17.1, 17.2, 25.1 and 25.1 biomaterials was at the levels of $86.24 \% \pm 5.6 \% ; 87.77 \% \pm 4.24 \% ; 88.6 \% \pm 4.44 \% ; 87.94 \% \pm 3.37 \%$, respectively. A statistical analysis has shown that there was no statistical significance between the viability of cells incubated with biocomposites containing polyphenols extracted from common sage (17.2 and 25.2) and the ones that did not contain extracts (17.1 and 25.1) However, the slight decrease in the metabolic activity of L929 cells was found to be statistically significant when compared with the physiological viability of the control cells.

\subsubsection{Cell Colonization of Composites}

The adhesion of L929 murine fibroblasts after 5 days of exposure to polyvinylpyrrolidone/sodium alginate/hydroxyapatite composites enriched with polyphenols extracted from common sage (Salvia officinalis) within their surface was investigated (Figures 9 and 10).

It has been shown that fibroblasts are able to colonize the composite, however, with a different effectiveness which depends on the composition of the individual material. The number of cells identified on the biomaterial surface was as follows: 17.1-24.67 \pm 6.03 , $17.2-27.00 \pm 6.56,25.1-78.00 \pm 14.00$, and 25.2-12.00 \pm 2.65 . In the case of matrices 17.1 and 17.2, the number of nuclei per area was slightly higher for the composite 17.2. However, the difference was not statistically significant. In contrast, biocomposite 25.2 containing the polyphenols from common sage, was a less favorable environment for L929 cell adhesion and expansion compared to composite 25.1 lacking the extract. The addition of gelatin was important in the context of cell adhesion which is visible in the nuclei numbers in composite 17.1 (no gelatin) and 25.1 (with gelatin). No differences in the L929 cells morphology were observed between the composites containing the extract and the ones lacking the extract addition. 


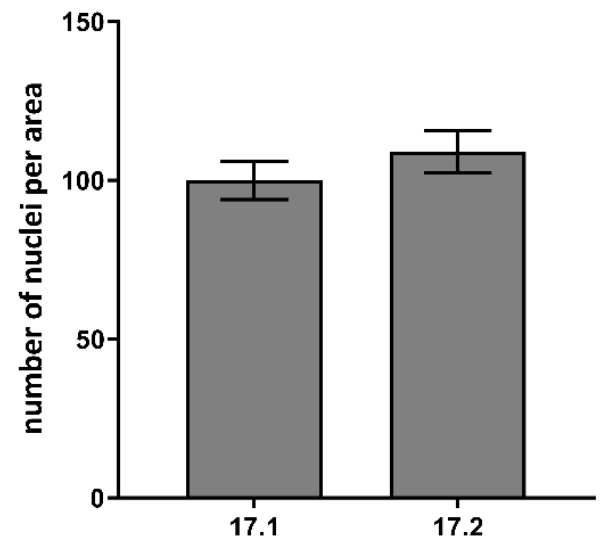

(a)

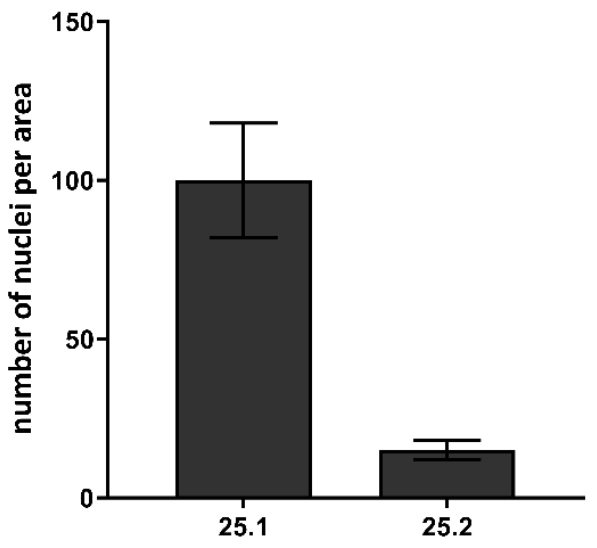

(b)

Figure 9. The number of nuclei per area visualized on the surface of biocomposites: (a) 17.1 and 17.2; (b) 25.1 and 25.2 after 5 days of incubation. The mean \pm SD number of cell nuclei visible on at least 3 fields was counted. The 17.1 material constitutes the reference for 17.1, whereas 25.1 a reference for 25.2 . The control material was set as $100 \%$
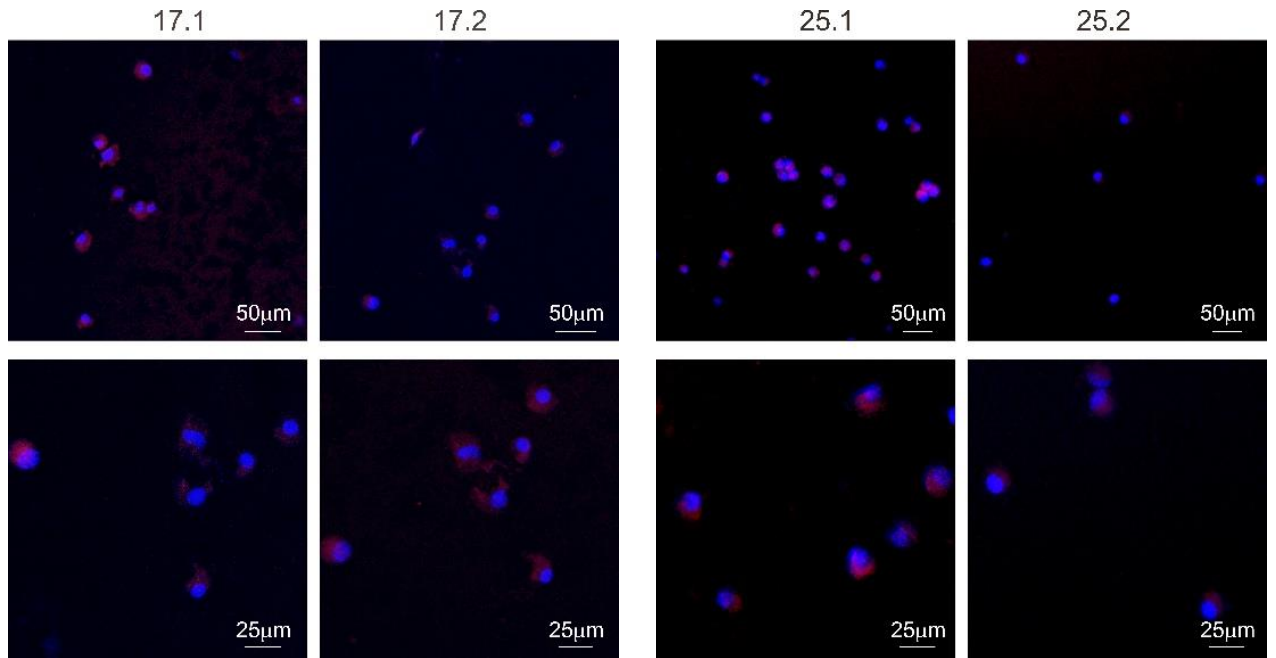

Figure 10. Visualization of L929 cells adhesion and expansion on the surface of biocomposites (17.1, 17.2, 25.1 and 25.2) after 5 days. The nuclei were stained with $300 \mathrm{nM}$ 2-(4-amidinophenyl)-1H-indole6-carboxamidine (DAPI) and actin filaments with phalloidin conjugated with iFluor 594. Samples were imaged with the following wavelength values of excitation and emission: 405 and 430-480 nm for DAPI, 590 and 615-630 nm for iFluor 594 conjugated antibody. Leica Application Suite X (LAS X; Leica Microsystems) was used for cell imaging.

\subsubsection{Immunocompatibility of THP1-Blue NF-kB Human Monocytes with Composites}

To determine the stimulatory effects of biocomposites, the activation of the NF- $\mathrm{B}$ factor in monocytes was determined. THP1-Blue monocytes, as a bioindicator of the composites' ability to induce immune cell activation, were used. Thus, because monocyte activity is crucial for the induction of a first (inflammatory) stage of the healing process, we attempted to evaluate the influence of the polyvinylpyrrolidone/sodium alginate/hydroxyapatite composites enriched with polyphenols extracted from common sage (Salvia officinalis) on the NF-kB induction in THP1-Blue monocytes.

It has been shown that after a $24 \mathrm{~h}$ incubation of THP1-Blue cells in the milieu of polyphenol-enriched materials, stimulation above the cut-off value was achieved not only for the positive control with PMA but also in cultures with the tested composites. 
These values were statistically significant in relation to the cut-off value (unstimulated culture) (Figure 11). Moreover, the degree of stimulation in the composites enriched with polyphenols extracted from common sage (17.2 and 25.2) was statistically significantly higher than in the control matrices containing no extract (17.1 and 25.1).

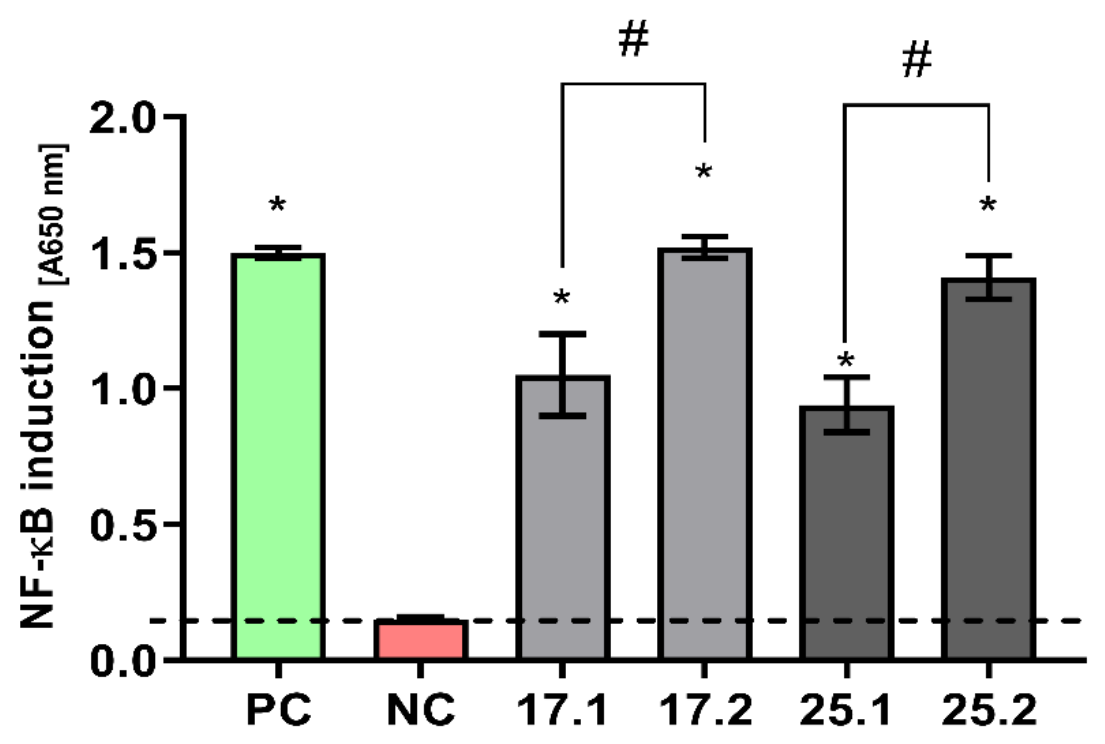

Figure 11. NF-kB induction in THP1-Blue monocytes incubated for $24 \mathrm{~h}$ with biocomposites. The negative control (NC) of the monocyte's activation (cut-off line) consisted of cells incubated without composites. The positive control (PC) of the monocyte's activation consisted of monocytes stimulated with PMA (100 ng/mL). The data are presented as the mean $\pm \mathrm{SD}, \mathrm{n}=6$. The dashed line indicates the physiological level $(0.151 \pm 0.008)$ of the nonstimulated monocytes. ${ }^{*} p$ values $(<0.05)$ calculated in comparison to the untreated cell cultures. \#-statistical significance between biocomposites enriched with polyphenols extracted from common sage and their reference (17.1 vs. 17.2 and 25.1 vs. 25.2).

\section{Discussion}

Composites based on polymers reinforced with HA and modified with common sage extract can be used in regenerative medicine of the skeletal system. The results presented indicate that polyphenols are released from the prepared composites. In this study, the XRD analysis of the synthesized hydroxyapatite showed that the material is characterized with a hexagonal structure. What is more, the analysis of the FT-IR spectrum indicated the presence of peaks and functional groups of ceramic material that showed osteoconductive properties. Comparing the obtained spectrum FT-IR of composites with pure components, one can observe the peaks coming from PVP. Furthermore, the signal from HA at $550 \mathrm{~cm}^{-1}$ occurs in the composite's spectra with common sage.

To investigate the behavior of the polymer-ceramic composites in fluids simulating the human body environment, in vitro investigations were performed. The biomaterials were incubated in PBS, Ringer's solution, artificial saliva, and distilled water. The $\mathrm{pH}-$ measurements of the artificial saliva solution revealed the greatest changes which were related to the partial degradation that occurred. Probably, the ions released from composites and the HA during the incubation lead to the $\mathrm{pH}$ increasing, causing a slightly basic solution [60]. However, no rapid changes of $\mathrm{pH}$ value were observed for samples immersed in PBS and Ringer's solution. In these cases, the new apatite layers were formed on the surface. Moreover, after 14 days of incubation in distilled water, swelling capacity was lower for the polymer-ceramic composite with common sage (17.2 and 25.2) than polymer matrices (17 and 25). However, the lowest values of Se were recorded for extract-free composites (17.1 and 25.1). The liquid medium penetration into composite materials structure was also slower. The antioxidant activity and TPC of Salvia officinalis extract were evaluated using the Folin-Ciocâlteu method and DPPH method. TPC for common sage equals 
$16.21 \pm 0.58 \mathrm{mg} \mathrm{GAE} \cdot \mathrm{g}^{-1}$ d.w., whereas the percentage of inhibition and the value reached $86.06 \pm 0.49 \%$. The evaluation of antioxidant activity as well as TPC was performed with the results by Francik et al. [35]. In accordance with the results shown, these values were dependent on the harvest period and drying method of the plant. The values of antioxidant capacity and TPC of the extract obtained with hydrochloric acid in $80 \%$ methanol were in the range $50.9 \pm 9.4-60.5 \pm 8.8 \%$. and $11.6 \pm 5.6 .-17.1 \pm 7.1 \mathrm{mg} \mathrm{GAE} \mathrm{g}^{-1}$ d.w., respectively. The extraction from the plant was carried out by shaking at room temperature for $2 \mathrm{~h}$ with an Elpan shaker. Higher values of radical scavenging activity of extract obtained in our research may be caused by longer extraction time as well as the higher temperature of the process. Furthermore, the kinetics of polyphenol release from polymer-ceramic composites was examined. It proves that this process was gradual, which is crucial in the drug delivery system. Moreover, it was shown that the addition of GE resulted in a more effective extract release from materials. The addition of an aqueous extract of common sage increased the biological value of the obtained composites.

The SEM analysis of the composites in selected artificial biological fluids showed changes in morphology before and after incubation. Newly formed apatite layers could be observed in PBS, which is a very desirable effect due to the bioactivity of the composite. Detailed EDS analysis revealed the presence of calcium and phosphorus, which make up the hydroxyapatite ceramics. This fact has a positive effect on the osteoconductive properties of the bone cells, a significant factor in orthopedic applications. In the case of samples incubated in an artificial saliva solution, degradation was observed. This is due to the slightly acidic $\mathrm{pH}$ of the incubation fluid. During the degradation process of the polymer matrix in Ringer's fluid, hydroxyapatite crystals were exposed, and the process itself was slower than in artificial saliva. Furthermore, the surface roughness analysis showed that the tested biomaterial samples were not perfectly flat.

The performed analysis of the cytocompatibility of composites gave satisfactory results and confirmed the safety and application potential of the presented materials, as biomaterials are considered safe at the in vitro level in the absence of cytotoxic activity mediated by them. In this study, we have shown that polyvinylpyrrolidone/sodium alginate/hydroxyapatite composites met the ISO 10993-5:2009 criterion for maintaining the in vitro viability of at least $70 \%$ of the murine fibroblast cells exposed to the biomaterial. L929 cells are the cell type that participates in the early stages of the wound healing process. Moreover, they are able to easily adhere and proliferate on a variety of biomaterial surfaces [61]. The murine fibroblast L929 cell line was used to investigate cell adhesion and morphology on the surface of the composites.

It was apparent that the morphology of L929 mouse fibroblast cells was similar on the composites with the sage extracts to the ones without extracts. There was no evidence that sage extract increased the adhesion and proliferation of L929 cells. In the case of the tested composites, the addition of gelatin significantly increased the number of cells adhering to the surface of composite (17.1 vs. 25.1). Thus, the polyvinylpyrrolidone/sodium alginate/hydroxyapatite composites enriched with polyphenols extracted from common sage, can be considered as composites to be used as a substrate to support the adhesion and proliferation of L929 mouse fibroblasts and should be further tested. Most organ and tissue damage resulting from congenital defects, trauma or chronic disease is treated surgically or pharmacologically [1,2]. As has been mentioned, great emphasis has been placed on intelligent, bioactive biomaterials which offer great potential for regenerative medicine, by, among other properties, stimulating surrounding tissues or delivering active components such as drugs or biomolecules [3]. Thus, apart from the lack of cytotoxicity, newly synthesized composites should exhibit features promoting the healing process. The first immune cells that emerge at the site of trauma and are involved in the healing process and tissue rearrangement are monocytes. They regulate immune-tissue homeostasis due to the secretion of cytokines and chemokines [62]. The role and the activity of monocytes in postimplantation processes is essential for the clearance of damaged cells and disintegrated tissues from the site of the trauma. The biological modification of biocomposites can 
facilitate the transition of monocytes into the active state, which in turn will facilitate the postimplantation processes [63].

The immunomodulatory properties of sage polysaccharides have been described by Cape et al. and Ghorbani and Esmaeilizadeh [34,64]. The evaluation of the activation of THP1-Blue monocytes via the NF- $\mathrm{KB}$ transcription factor after incubation with polyvinylpyrrolidone/sodium alginate/hydroxyapatite composites enriched with polyphenols proved that common sage extracts are able to activate monocytes in a statistically significant way compared to composites lacking the extracts. Thus, composites with common sage extracts may promote the regeneration process by monocyte migration and activation at the site of injury. In order to fully answer the question of whether tested biocomposite immunostimulation facilitates regeneration processes, further experiments should be conducted.

\section{Conclusions}

In our study, we successfully prepared a bioactive ceramic-polymer composite modified with common sage. Physicochemical analysis, incubation studies, as well as cytotoxicity testing of the proposed solution were performed. Considering the impressive biocompatibility of the materials used and their biodegradability, the potential utility of these biomaterials in bone tissue engineering, as well as bone regeneration, has attracted much attention, mainly due to HA, which is known for its osteoconductive properties. Moreover, the gradual release in time of the active ingredients from common sage, further enhances the biological value of the biomaterial, given the broad spectrum of action of the extract from this plant. The overall biological evaluation of the composites places them as a very promising candidate for future biomedical engineering applications. Therefore, the obtained results, considering the potential of the presented biomaterials, suggest the necessity of further research, especially in the aspect of osteogenesis.

Author Contributions: Conceptualization, D.S., W.F., K.P. and K.R.; methodology, W.F., D.S., K.P., A.S., M.W., M.S. and K.R.; software, D.S., W.F. and K.P.; validation, K.R. and A.S.-K.; formal analysis, D.S., W.F. and K.P.; investigation, D.S., W.F., K.P., A.S., M.W., M.S.; resources, A.S.-K. and K.R.; data curation, D.S., W.F., A.S. and M.W.; writing—original draft preparation, D.S., W.F., K.P., A.S., M.W. and M.S.; writing - review and editing, A.S.-K. and K.R.; visualization, D.S. and W.F.; supervision, A.S.-K. and K.R.; project administration, A.S.-K.; funding acquisition, A.S.-K. All authors have read and agreed to the published version of the manuscript.

Funding: This research was funded by Foundation for Polish Science, grant number POIR.04.04.0000-16D7/18.

Institutional Review Board Statement: Not applicable.

Informed Consent Statement: Not applicable.

Data Availability Statement: The data that support the findings of this study are contained within the article.

Acknowledgments: The "Multifunctional biologically active composites for applications in bone regenerative medicine" project is carried out within the TEAM-NET program of the Foundation for Polish Science financed by the European Union under the European Regional Development Fund. The authors gratefully acknowledge financial support. The authors thank Sylwia Michlewska for assisting in confocal microscopy imaging performed in the Laboratory of Microscopic Imaging and Specialized Biological Techniques (Faculty of Biology and Environmental Protection, University of Lodz).

Conflicts of Interest: The authors declare no conflict of interest. 


\section{References}

1. Thatoi, H.; Kumar Das, S.; Mohapatra, S. Bioresource Utilization and Management: Applications in Therapeutics, Biofules, Agriculture and Environmental Science; CRC Press: Boca Raton, FL, USA; Apple Academic Press: Burlington, ON, Canada, 2021; ISBN 9781771889339.

2. Sobczak-Kupiec, A.; Drabczyk, A.; Florkiewicz, W.; Głąb, M.; Kudłacik-Kramarczyk, S.; Słota, D.; Tomala, A.; Tyliszczak, B. Review of the applications of biomedical compositions containing hydroxyapatite and collagen modified by bioactive components. Materials 2021, 14, 2096. [CrossRef]

3. Busch, A.; Jäger, M.; Mayer, C.; Sowislok, A. Functionalization of synthetic bone substitutes. Int. J. Mol. Sci. 2021, 22, 4412. [CrossRef]

4. Rodríguez, M.; Gómez-Gil, V.; Pérez-Köhler, B.; Pascual, G.; Bellón, J.M. Polymer hernia repair materials: Adapting to patient needs and surgical techniques. Materials 2021, 14, 2790. [CrossRef]

5. Baino, F.; Fiume, E. Elastic mechanical properties of 45S5-based bioactive glass-ceramic scaffolds. Materials $2019,12,3244$. [CrossRef]

6. Tatullo, M.; Genovese, F.; Aiello, E.; Amantea, M.; Makeeva, I.; Zavan, B.; Rengo, S.; Fortunato, L. Phosphorene is the new graphene in biomedical applications. Materials 2019, 12, 2301. [CrossRef]

7. Kołodziejska, B.; Kaflak, A.; Kolmas, J. Biologically inspired collagen/apatite composite biomaterials for potential use in bone tissue regeneration-A review. Materials 2020, 13, 1748. [CrossRef]

8. Koons, G.L.; Diba, M.; Mikos, A.G. Materials design for bone-tissue engineering. Nat. Rev. Mater. 2020, 5, 584-603. [CrossRef]

9. Shi, P.; Liu, M.; Fan, F.; Yu, C.; Lu, W.; Du, M. Characterization of Natural Hydroxyapatite Originated from Fish Bone and Its Biocompatibility with Osteoblasts; Elsevier B.V: Amsterdam, The Netherlands, 2018; Volume 90, ISBN 8641186332275.

10. Gonçalves, A.M.; Moreira, A.; Weber, A.; Williams, G.R.; Costa, P.F. Osteochondral Tissue Engineering: The Potential of Electrospinning and Additive Manufacturing. Pharmaceutics 2021, 13, 983. [CrossRef]

11. Mohd Roslan, M.R.; Mohd Kamal, N.L.; Abdul Khalid, M.F.; Mohd Nasir, N.F.; Cheng, E.M.; Beh, C.Y.; Tan, J.S.; Mohamed, M.S The state of starch/hydroxyapatite composite scaffold in bone tissue engineering with consideration for dielectric measurement as an alternative characterization technique. Materials 2021, 14, 1960. [CrossRef]

12. Montalbano, G.; Molino, G.; Fiorilli, S.; Vitale-Brovarone, C. Synthesis and incorporation of rod-like nano-hydroxyapatite into type I collagen matrix: A hybrid formulation for 3D printing of bone scaffolds. J. Eur. Ceram. Soc. 2020, 40, 3689-3697. [CrossRef]

13. Pryadko, A.; Surmeneva, M.A.; Surmenev, R.A. Review of hybrid materials based on polyhydroxyalkanoates for tissue engineering applications. Polymers 2021, 13, 1738. [CrossRef]

14. Teghil, R.; Curcio, M.; Bonis, A. De Substituted Hydroxyapatite, Glass, and Glass-Ceramic Thin Films Deposited by Nanosecond Pulsed Laser Deposition (PLD) for Biomedical Applications: A Systematic Review. Coatings 2021, 11, 811. [CrossRef]

15. Nasar, A. Hydroxyapatite and Its Coatings in Dental Implants; Elsevier Inc.: Amsterdam, The Netherlands, 2018; ISBN 9780128137598.

16. Bai, Y.; Kanno, T.; Tatsumi, H.; Miyamoto, K.; Sha, J.; Hideshima, K.; Matsuzaki, Y. Feasibility of a three-dimensional porous uncalcined and unsintered hydroxyapatite/poly-D/L-lactide composite as a regenerative biomaterial in maxillofacial surgery. Materials 2018, 11, 2047. [CrossRef]

17. Bastos, A.R.; da Silva, L.P.; Maia, F.R.; Pina, S.; Rodrigues, T.; Sousa, F.; Oliveira, J.M.; Cornish, J.; Correlo, V.M.; Reis, R.L. Lactoferrin-Hydroxyapatite Containing Spongy-Like Hydrogels for Bone Tissue Engineering. Materials 2019, 13, 2074. [CrossRef]

18. Atala, A.; Lanza, R.; Mikos, A.G.; Nerem, R. Principles of Regenerative Medicine, 3rd ed.; London Elsevier: London, UK; Academic Press: Cambridge, MA, USA, 2019.

19. Prochor, P.; Mierzejewska, Ż.A. Bioactivity of PEEK GRF30 and Ti6Al4V SLM in simulated body fluid and hank's balanced salt solution. Materials 2021, 14, 2059. [CrossRef]

20. Siddiqui, H.A.; Pickering, K.L.; Mucalo, M.R. A review on the use of hydroxyapatite- carbonaceous structure composites in bone replacement materials for strengthening purposes. Materials 2018, 11, 1813. [CrossRef]

21. Pandele, A.M.; Constantinescu, A.; Radu, I.C.; Miculescu, F.; Voicu, S.I.; Ciocan, L.T. Synthesis and characterization of PLA-microstructured hydroxyapatite composite films. Materials 2020, 13, 274. [CrossRef]

22. Slota, D.; Gląb, M.; Tyliszczak, B.; Dogulas, T.E.L.; Rudnicka, K.; Miernik, K.; Urbaniak, M.M.; Rusek-Wala, P.; Sobczak-upiec, A. Composites based on hydroxyapatite and whey protein isolate for applications in bone regeneration. Materials 2021, 14, 2317. [CrossRef]

23. Grant, J.J.; Pillai, S.C.; Perova, T.S.; Hehir, S.; Hinder, S.J.; McAfee, M.; Breen, A. Electrospun fibres of chitosan/PVP for the effective chemotherapeutic drug delivery of 5-fluorouracil. Chemosensors 2021, 9, 70. [CrossRef]

24. Ozkan, G.; Franco, P.; Capanoglu, E.; De Marco, I. PVP/flavonoid coprecipitation by supercritical antisolvent process. Chem. Eng. Process.-Process. Intensif. 2019, 146, 107689. [CrossRef]

25. López-Calderón, H.D.; Avilés-Arnaut, H.; Galán Wong, L.J.; Almaguer-Cantú, V.; Laguna-Camacho, J.R.; Calderón-Ramón, C.; Escalante-Martínez, J.E.; Arévalo-Niño, K. Electrospun Polyvinylpyrrolidone-Gelatin and Cellulose Acetate Bi-Layer Scaffold Loaded with Gentamicin as Possible Wound Dressing. Polymers 2020, 12, 2311. [CrossRef]

26. Voronova, M.; Rubleva, N.; Kochkina, N.; Afineevskii, A.; Zakharov, A.; Surov, O. Preparation and characterization of polyvinylpyrrolidone/cellulose nanocrystals composites. Nanomaterials 2018, 8, 1011. [CrossRef] 
27. Maulvi, F.A.; Patel, P.J.; Soni, P.D.; Desai, A.R.; Desai, D.T.; Shukla, M.R.; Ranch, K.M.; Shah, S.A.; Shah, D.O. Novel Poly(vinylpyrrolidone)-Coated Silicone Contact Lenses to Improve Tear Volume during Lens Wear: In Vitro and in Vivo Studies. ACS Omega 2020, 5, 18148-18154. [CrossRef] [PubMed]

28. Pereira, G.R.S.; Taveira, S.F.; Cunha-Filho, M.; Marreto, R.N. The Effects of Fillers and Binders on the Accuracy of Tablet Subdivision. AAPS PharmSciTech 2018, 19, 2929-2933. [CrossRef] [PubMed]

29. Bujak, T.; Wasilewski, T.; Nizioł-Łukaszewska, Z. Role of macromolecules in the safety of use of body wash cosmetics. Colloids Surf. B Biointerfaces 2015, 135, 497-503. [CrossRef] [PubMed]

30. Chiang, N.; Ray, S.; Lomax, J.; Goertzen, S.; Komarnytsky, S.; Ho, C.; Munafo, J.P. Modulation of Brain-Derived Neurotrophic Factor (BDNF) Signaling Pathway by Culinary Sage (Salvia officinalis L). Int. J. Mol. Sci. 2021, 14, 7382. [CrossRef] [PubMed]

31. Vergine, M.; Nicolì, F.; Negro, C.; Luvisi, A.; Nutricati, E.; Accogli, R.A.; Sabella, E.; Miceli, A. Phytochemical profiles and antioxidant activity of salvia species from southern Italy. Rec. Nat. Prod. 2019, 13, 205-215. [CrossRef]

32. Kolac, U.K.; Ustuner, M.C.; Tekin, N.; Ustuner, D.; Colak, E.; Entok, E. The Anti-Inflammatory and Antioxidant Effects of Salvia officinalis on Lipopolysaccharide-Induced Inflammation in Rats. J. Med. Food 2017, 20, 1193-1200. [CrossRef] [PubMed]

33. Ovidi, E.; Masci, V.L.; Zambelli, M.; Tiezzi, A.; Vitalini, S.; Gorzoli, S. Laurus nobilis, Salvia sclarea and Salvia officinalis Essential Oils and Hydrolates: Evaluation of Liquid and Vapor Phase Chemical Composition and Biological Activitie. Plants 2021, 4, 1-17. [CrossRef]

34. Ghorbani, A.; Esmaeilizadeh, M. Pharmacological properties of Salvia officinalis and its components. J. Tradit. Complementary Med. 2017, 7, 433-440. [CrossRef]

35. Francik, S.; Francik, R.; Sadowska, U.; Bystrowska, B.; Zawiślak, A.; Knapczyk, A.; Nzeyimana, A. Identification of phenolic compounds and determination of antioxidant activity in extracts and infusions of salvia leaves. Materials 2020, 13, 5811. [CrossRef]

36. Boufadi, M.Y.; Keddari, S.; Moulai-Hacene, F.; Chaa, S. Chemical composition, antioxidant and anti-inflammatory properties of Salvia officinalis extract from Algeria. Pharmacogn. J. 2021, 13, 506-515. [CrossRef]

37. Marchica, A.; Cotrozzi, L.; Detti, R.; Lorenzini, G.; Pellegrini, E.; Petersen, M.; Nali, C. The biosynthesis of phenolic compounds is an integrated defence mechanism to prevent ozone injury in salvia officinalis. Antioxidants 2020, 9, 1274. [CrossRef] [PubMed]

38. Šojić, B.; Tomović, V.; Savanović, J.; Kocić-Tanackov, S.; Pavlić, B.; Jokanović, M.; Milidrag, A.; Martinović, A.; Vujadinović, D.; Vukić, M. Sage (Salvia officinalis L.) essential oil as a potential replacement for sodium nitrite in dry fermented sausages. Processes 2021, 9, 424. [CrossRef]

39. Elkomy, M.M.; Elsaid, F.G. Anti-osteoporotic effect of medical herbs and calcium supplementation on ovariectomized rats. J. Basic Appl. Zool. 2015, 72, 81-88. [CrossRef]

40. Pluta, K.; Florkiewicz, W.; Malina, D.; Rudnicka, K.; Michlewska, S.; Królczyk, J.B.; Sobczak-Kupiec, A. Measurement methods for the mechanical testing and biocompatibility assessment of polymer-ceramic connective tissue replacements. Meas. J. Int. Meas. Confed. 2021, 171, 108733. [CrossRef]

41. Florkiewicz, W.; Malina, D.; Pluta, K.; Rudnicka, K.; Gajewski, A.; Olejnik, E.; Tyliszczak, B.; Sobczak-Kupiec, A. Assessment of cytotoxicity and immune compatibility of phytochemicals-mediated biosynthesised silver nanoparticles using Cynara scolymus. IET Nanobiotechnol. 2019, 13, 726-735. [CrossRef]

42. Gazińska, M.; Krokos, A.; Kobielarz, M.; Włodarczyk, M.; Skibińska, P.; Stępak, B.; Antończak, A.; Morawiak, M.; Płociński, P.; Rudnicka, K. Influence of hydroxyapatite surface functionalization on thermal and biological properties of poly(L-lactide)-and poly(l-lactide-co-glycolide)-based composites. Int. J. Mol. Sci. 2020, 21, 6711. [CrossRef]

43. Nazarpak, M.H.; Shahabi, S.; Najafi, F. Effect of Gamma Irradiation on Structural and Biological Properties of a PLGA-PEGHydroxyapatite Composite. Sci. World J. 2014, 1-9. [CrossRef]

44. Martins, A.P.S.; De Añastro, A.F.; Olmedo-Martínez, J.L.; Nabais, A.R.; Neves, L.A.; Mecerreyes, D.; Tomé, L.C. Influence of anion structure on thermal, mechanical and $\mathrm{CO} 2$ solubility properties of uv-cross-linked poly(Ethylene glycol) diacrylate iongels. Membranes 2020, 10, 46. [CrossRef] [PubMed]

45. Hamid, Z.A.A.; Lim, K.W. Evaluation of UV-crosslinked Poly(ethylene glycol) Diacrylate/Poly(dimethylsiloxane) Dimethacrylate Hydrogel: Properties for Tissue Engineering Application. Procedia Chem. 2016, 19, 410-418. [CrossRef]

46. Youness, R.A.; Taha, M.A.; Elhaes, H.; Ibrahim, M. Molecular modeling, FTIR spectral characterization and mechanical properties of carbonated-hydroxyapatite prepared by mechanochemical synthesis. Mater. Chem. Phys. 2017, 190, 209-218. [CrossRef]

47. Adzila, S.; Sopyan, I.; Hamdi, M. Mechanochemical synthesis of hydroxyapatite nanopowder: Effects of rotation speed and milling time on powder properties. Appl. Mech. Mater. 2012, 110-116, 3639-3644. [CrossRef]

48. Zhou, W.Y.; Wang, M.; Cheung, W.L.; Guo, B.C.; Jia, D.M. Synthesis of carbonated hydroxyapatite nanospheres through nanoemulsion. J. Mater. Sci. Mater. Med. 2008, 19, 103-110. [CrossRef]

49. Dhumale, V.A.; Gangwar, R.K.; Datar, S.S.; Sharma, R.B. Reversible aggregation control of polyvinylpyrrolidone capped gold nanoparticles as a function of $\mathrm{pH}$. Mater. Express 2012, 2, 311-318. [CrossRef]

50. Kamaruddin, K.; Edikresnha, D.; Sriyanti, I.; Munir, M.M.; Khairurrijal, K. Synthesis of Polyvinylpyrrolidone (PVP)-Green Tea Extract Composite Nanostructures using Electrohydrodynamic Spraying Technique. IOP Conf. Ser. Mater. Sci. Eng. 2017, 202, 1-8. [CrossRef]

51. Pereira, R.; Tojeira, A.; Vaz, D.C.; Mendes, A.; Bártolo, P. Preparation and characterization of films based on alginate and aloe vera. Int. J. Polym. Anal. Charact. 2011, 16, 449-464. [CrossRef] 
52. Sobczak-Kupiec, A.; Pluta, K.; Drabczyk, A.; Włoś, M.; Tyliszczak, B. Synthesis and characterization of ceramic-polymer composites containing bioactive synthetic hydroxyapatite for biomedical applications. Ceram. Int. 2018, 44, 13630-13638. [CrossRef]

53. Turabee, M.H.; Thambi, T.; Duong, H.T.T.; Jeong, J.H.; Lee, D.S. A pH- and temperature-responsive bioresorbable injectable hydrogel based on polypeptide block copolymers for the sustained delivery of proteins: In vivo. Biomater. Sci. 2018, 6, 661-671 [CrossRef] [PubMed]

54. Wang, J.; Zheng, Y.; Wang, A. Synthesis and swelling behaviors of poly(sodium acrylate)/hydroxyapatite superabsorbent nanocomposites. Adv. Mater. Res. 2010, 96, 227-232. [CrossRef]

55. Saber-Samandari, S.; Saber-Samandari, S.; Gazi, M. Cellulose-Graft-Polyacrylamide/Hydroxyapatite Composite Hydrogel with Possible Application in Removal of Cu (II) Ions; Elsevier Ltd: Amsterdam, The Netherlands, 2013; Volume 73, ISBN 1591633311.

56. Nakaoki, T.; Yamashita, H. Bound states of water in poly(vinyl alcohol) hydrogel prepared by repeated freezing and melting method. J. Mol. Struct. 2008, 875, 282-287. [CrossRef]

57. Ricciardi, R.; Auriemma, F.; De Rosa, C.; Lauprêtre, F. X-ray Diffraction Analysis of Poly(vinyl alcohol) Hydrogels, Obtained by Freezing and Thawing Techniques. Macromolecules 2004, 37, 1921-1927. [CrossRef]

58. Hudz, N.; Yezerska, O.; Shanaida, M.; Sedláčková, V.H.; Wieczorek, P.P. Application of the Folin-Ciocalteu method to the evaluation of Salvia sclarea extracts. Pharmacia 2019, 66, 209-215. [CrossRef]

59. Ghadermazi, R.; Keramat, J.; Goli, S.A.H. Antioxidant activity of clove (Eugenia caryophyllata Thunb), oregano (Oringanum vulgare L) and sage (Salvia officinalis L) essential oils in various model systems. Int. Food Res. J. 2017, 24, $1628-1635$.

60. Sobczak-Kupiec, A.; Malina, D.; Piatkowski, M.; Krupa-Zuczek, K.; Wzorek, Z.; Tyliszczak, B. Physicochemical and biological properties of hydrogel/gelatin/ hydroxyapatite PAA/G/HAp/AgNPs composites modified with silver nanoparticles. J. Nanosci. Nanotechnol. 2012, 12, 9302-9311. [CrossRef] [PubMed]

61. Kumar, A.; Malik, A.K.; Acikbas, N.C.; Yaygingol, M.; Kara, F.; Mandal, H.; Basu, B. Cytocompatibility property evaluation of gas pressure sintered SiAlON-SiC composites with L929 fibroblast cells and Saos-2 osteoblast-like cells. Mater. Sci. Eng. 2012, 3, 464-469. [CrossRef]

62. Baht, G.S.; Vi, L.; Alman, B.A. The Role of the Immune Cells in Fracture Healing. Curr. Osteoporos. Rep. 2018, 16, 138-145. [CrossRef]

63. Khokhani, P.; Rahmani, N.R.; Kok, A.; Öner, F.C.; Alblas, J.; Weinans, H.; Kruyt, M.C.; Croes, M. Use of therapeutic pathogen recognition receptor ligands for osteo-immunomodulation. Materials 2021, 14, 1119. [CrossRef] [PubMed]

64. Capek, P.; Hř́balová, V. Water-soluble polysaccharides from Salvia officinalis L. possessing immunomodulatory activity. Phytochemistry 2004, 65, 1983-1992. [CrossRef] 